WIS-CS-72-164

COMPUTER SCIENCES DEPARTMENT

The University of Wisconsin

1210 West Dayton Street

Madison, Wisconsin 53706

DISCRETE BARS, CONDUCTIVE HEAT

TRANSFER, AND ELASTICITY

by

Donald Greenspan

Appendix: FORTRAN Program for Discrete Conductive Heat Transfer, by Sandie Turner Jones

Technical Report \#164

November 1972

Received October 24, 1972 


\section{DISCRETE BARS, CONDUCTIVE HEAT TRANSFER, AND ELASTICITY}

\section{Introduction}

Though the study of bars, or rods, is basic in structural analysis, heat transfer theory, and elasticity theory (see, e.g., refs. $[1,3,4$, 9-14] and the numerous references contained therein), most of the related models have been continuous and/or linear in nature. The intent of the present paper is to initiate a general computer oriented model which is discrete and nonlinear. For simplicity only, we will restrict attention to two dimensions, and, for convenience, we will describe an arithmetic, energy conserving n-body interaction model first.

\section{Discrete $n-$ Body Interaction}

For positive time step $\Delta t$, let $t_{k}=k \Delta t, k=0,1,2, \ldots$. At time $t_{k}$ let particle $P_{i}$ of mass $m_{i}$ be located at $\vec{x}_{i, k}=\left(x_{i, k}, y_{i, k}\right)$, have velocity $\vec{v}_{i, k}=\left(v_{i, k}, x^{\prime}, k, y\right)$, and have acceleration $\vec{a}_{i, k}=$ $\left(a_{i, k}, x^{\prime} a_{i, k}, y\right)$, for $i=1,2, \ldots n$. Position, velocity, and acceleration are assumed to be related by the typical, discrete formulas $[5,6]$ :

$$
\begin{aligned}
& \frac{\vec{v}_{i, k+1}+\vec{v}_{i, k}}{2}=\frac{\vec{x}_{i, k+1}-\vec{x}_{i, k}}{\Delta t} \\
& \vec{a}_{i, k}=\frac{\vec{v}_{i, k+1}-\vec{v}_{i, k}}{\Delta t} .
\end{aligned}
$$


If $\vec{F}_{i, k}=\left(F_{i, k, x}, F_{i, k, y}\right)$ is the force acting on $P_{i}$ at time $t_{k}$, then force and acceleration are assumed to be related by the discrete dynamical equation

$$
\vec{F}_{i, k}=m_{i} \vec{a}_{i, k}
$$

In particular, we will choose $\vec{F}_{i, k}$ to have a component of attraction which behaves like $\frac{\mathrm{p}}{\mathrm{r} \alpha}$ and a component of repulsion which behaves like $\frac{q}{r^{\beta}}$, where $p, q, \alpha$ and $\beta$ are non-negative parameters with $\alpha \geq 2, \beta \geq 2$, and where $r$ is the distance between a given pair of particles. For this purpose, let $r_{i j, k}$ be the distance between $P_{i}$ and $P_{j}$ at $t_{k}$. Then $\vec{F}_{i, k}$, the force exerted on $P_{i}$ by the remaining particles, is defined by

$$
\begin{aligned}
& \vec{F}_{i, k}=m_{i} \sum_{\substack{j=1 \\
j \neq i}}^{n}\left\{m _ { j } \left(-\frac{p \sum_{j=0}^{\alpha-2}\left(r_{i j, k}^{\xi} r_{i j, k+1}^{\alpha-\xi-2}\right.}{r_{i j, k}^{\alpha-1} r_{i j, k+1}^{\alpha-1}\left(r_{i j, k+1}+r_{i j, k}\right)}\right.\right.
\end{aligned}
$$

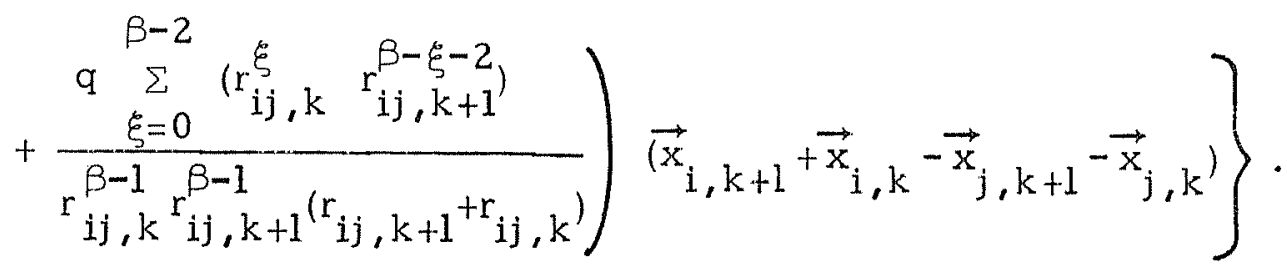

The particular value of $(2.4)$ lies in the observation that if one defines system work $W$ from $t_{0}$ to $t_{N}$ by 


$$
\left.W=\sum_{i=1}^{n} \sum_{k=0}^{N}\left[\vec{x}_{i, k+1}-\vec{x}_{i, k}\right) \cdot \vec{F}_{i, k}\right],
$$

system kinetic energy $K_{k}$ at time $t_{k}$ by

$$
\mathrm{K}_{k}=\sum_{i=0}^{\mathrm{n}}\left[\frac{1}{2} m_{i}\left(v_{i, k, x}^{2}+v_{i, k, y}^{2}\right)\right],
$$

and system potential energy $V_{k}$ at time $t_{k}$ by

$$
V_{k}=\sum_{\substack{i, j=1 \\ i<j}}^{n}\left[\left(-\frac{p}{r_{i j, k}^{\alpha-1}}+\frac{q}{r_{i j, k}^{\beta-1}}\right) m_{i} m_{j}\right],
$$

then, as in [5] and [6],

$$
\mathrm{K}_{\mathrm{N}}+\mathrm{V}_{\mathrm{N}}=\mathrm{K}_{0}+\mathrm{V}_{0^{\prime}} \quad \mathrm{N}=0,1,2, \ldots,
$$

which is the classical law of conservation of energy.

\section{The Solid State Building Block}

In modeling a solid, we will attempt to simulate contemporary physical thought $[2,8]$, in which molecules and atoms exhibit small vibrations within the solid. For this purpose, consider first a system of only two particles, $\mathrm{P}_{1}$ and $\mathrm{P}_{2}$, of equal mass, which interact according to (2.4). Assume that the force between the particles is zero. Then, from (2.4), 
(3. 1)

$$
\frac{-p \sum_{\xi=0}^{\alpha-2}\left(r_{i j, k}^{\xi} r_{i j, k+1}^{\alpha-\xi-2}\right)}{r_{i j, k}^{\alpha-1} r_{i j, k+1}^{\alpha-1}\left(r_{i j, k+1}^{+r_{i j, k}}\right)}+\frac{\sum_{\sum_{i j}=0}^{\beta-2}\left(r_{i j, k}^{\xi} r_{i j, k+1}^{\beta-\xi-2}\right)}{r_{i j, k}^{\beta-1} r_{i j, k+1}^{\beta-1}\left(r_{i j, k+1}+r_{i j, k}\right)}=0 .
$$

But, if there is zero force between the two particles, then $r_{i j, k}=$ $r_{i j, k+1}$, so set $r_{i j, k}=r_{i j, k+1}=r$ in $(3.1)$ to yield

$$
\frac{-p \sum_{\xi=0}^{\alpha-2} r^{\alpha-2}}{r^{2 \alpha-2}}+\frac{q \sum_{\xi=0}^{\beta-2} r^{\beta-2}}{r^{2 \beta-2}}=0 .
$$

Thus, for $\beta \geq \alpha$,

$$
-\operatorname{pr}^{-\alpha}(\alpha-1)+\operatorname{qr}^{-\beta}(\beta-1)=0
$$

or, finally,

$$
r=\sqrt[\beta-\alpha]{\frac{q(\beta-1)}{p(\alpha-1)}}
$$

Consider next a system of only three particles, $\mathrm{P}_{1}, \mathrm{P}_{2}$ and $\mathrm{P}_{3}$, of equal masses, whose mutual distances apart are given by (3.3). Since no force acts between any two of the particles, it follows that there is no force acting upon any one of the three. Such a configuration of particles is therefore exceptionally stable and will be called a triangular building block. 
When considering a solid we will decompose it into triangular building blocks. In this fashion, the force on any particular particle due to its nearby neighbors will be zero. By an appropriate choice of parameters, the force on any particle due to more distant particles will be made small, thus achieving the small vibrations desired.

To illustrate, let the six particles $\mathrm{P}_{1}, \mathrm{P}_{2}, \mathrm{P}_{3}, \mathrm{P}_{4}, \mathrm{P}_{5}, \mathrm{P}_{6}$ be located at the vertices of the four triangular building blocks of the triangular region $O A B$, shown in Figure 3.1. Assume that $m_{i} \equiv 1$, $p=q=1, \alpha=7$, and $\beta=10$, so that $r=\sqrt[3]{1.5}$. The particles' initial positions are, then,

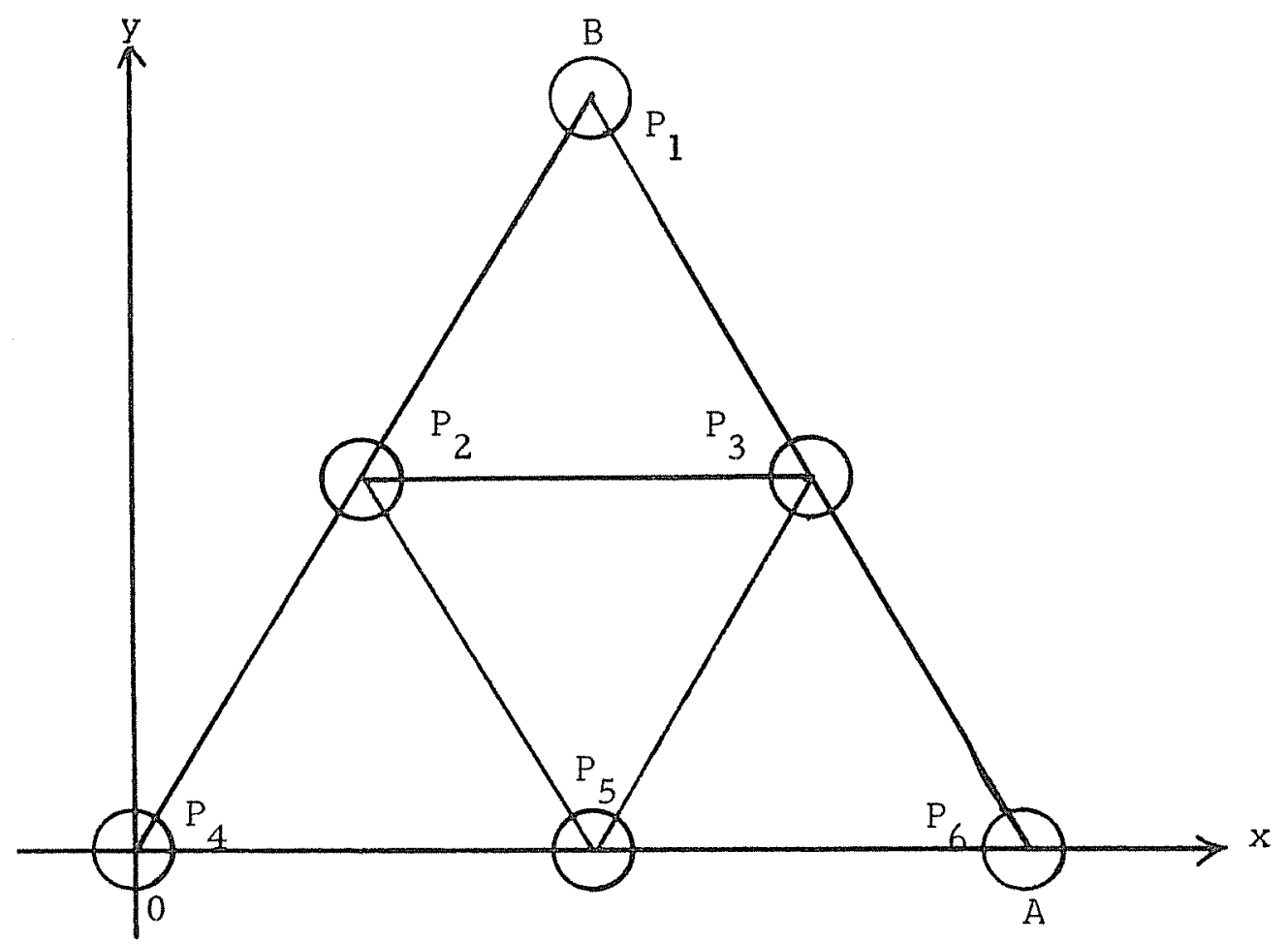

Figure 3.1 


$$
\begin{aligned}
& \mathrm{P}_{1}:(1.14471,1.98270) \\
& \mathrm{P}_{2}:(0.57236,0.99135) \\
& \mathrm{P}_{3}:(1.71707,0.99135) \\
& \mathrm{P}_{4}:(0,0) \\
& \mathrm{P}_{5}:(1.14471,0) \\
& \mathrm{P}_{6}:(2.28943,0) .
\end{aligned}
$$

Assign to each particle a $\overrightarrow{0}$ initial velocity. Finally, let particles $\mathrm{P}_{4}$ and $\mathrm{P}_{6}$ be fixed and allow the remaining particles to move under force law (2.4). For $\Delta t=0.05$ and for 2500 time steps, the motions of $\mathrm{P}_{1}, \mathrm{P}_{2}, \mathrm{P}_{3}$ and $\mathrm{P}_{5}$ were generated from $(2.1)-(2.4) . \mathrm{P}_{1}$ and $\mathrm{P}_{5}$ exhibited small oscillations in the vertical directly only, while $\mathrm{P}_{2}$ and $\mathrm{P}_{3}$ exhibited small two dimensional oscillations. The maximum distance, for example, that $P_{1}$ moved from its initial position was approximately 0.02 , and this occurred at approximately every one hundred time steps. The running time on the UNIVAC 1108 was 4 minutes. The basic computer program used, which is also typical of all examples which follow, was that of Jones [7].

Note that the magnitudes of the oscillations described above can be controlled completely by the appropriate choices of $p, q, \alpha$, and $\beta$.

\section{Flow of Heat in a Bar}

Let us now develop the basic concepts of discrete conductive heat 
transfer by concentrating on the prototype problem of heat flow in a bar. Physically, the problem is formulated as follows. Let the region bounded by rectangle $O A B C$, as shown in Figure 3.1 , represent a bar. Let $|O A|=a,|O C|=c$. A section of the boundary of the bar is heated. The problem is to describe the flow of heat through the bar. Our discrete approach to the problem proceeds as follows. First, subdivide the given region into triangular building blocks, one such possible subdivision of which is shown in Figure 3.2 for the parameter choices $m_{i} \equiv 1, \quad p=q=1, \alpha=7, \beta=10, a \sim 11, c \sim 2$. Note that from (3.3), $r \sim 1.1447142426$.

Now, by heating a section of the boundary of the bar, we will mean increasing the velocity, and hence the potential energy, of some of the particles whose centers are on OABC. By the temperature $T_{i, k}$ of particle $P_{i}$ at time $t_{k}$, we will mean the following. Let $M$ be a fixed positive integer and let $K_{i, k}$ be the kinetic energy of $P_{i}$ at $t_{k}$. Then $\mathrm{T}_{i, k}$ is defined by

$$
T_{i, k}=\frac{1}{M} \sum_{j=k-M+1}^{k} K_{i, j^{\prime}}
$$

which is, of course, the arithmetic mean of $\mathrm{P}_{i}{ }^{\text {'s }}$ kinetic energies at M consecutive time steps. By the flow of heat through the bar we will mean the transfer to other particles of the bar of the kinetic energy added at the boundary. Finally, to follow the flow of heat through the 
bar one need only follow the motion of each particle and, at each time step, record its temperature.

To illustrate, consider the bar shown in Figure 3.2 with the parameter choices given above, that is, $m_{i} \equiv 1, p=q=1, \alpha=7, \beta=10$, $\mathrm{a} \sim 11, \mathrm{c} \sim 2$. Assume that a strong heat source is placed above $\mathrm{P}_{6}$, and then removed, in such a fashion that $\vec{v}_{5,0}=\left(\frac{-\sqrt{2}}{2}, \frac{-\sqrt{2}}{2}\right)$, $\vec{v}_{6,0}=(0,-1), \vec{v}_{7,0}=\left(\frac{\sqrt{2}}{2}, \frac{-\sqrt{2}}{2}\right)$, while all other initial velocities are $\overrightarrow{0}$. With regard to temperature calculation, assume that the velocities of all particles prior to $t_{0}$ were $\overrightarrow{0}$. As regards the choice of $\mathrm{M}$, which is a difficult choice to make, one would usually wish to choose it relatively large, since the use of an average is, generally, more meaningful when the number of quantities being averaged is relatively large. We shall arbitrarily set $\mathrm{M}=20$. From the resulting calculations with $\Delta t=0.025$, Figures $3.3-3.7$ show the constant temperature contours $T=0.1,0.06,0.025,0.002$ at $t_{5}, t_{10}, t_{15}$, $t_{20}$ and $t_{25}$, respectively. The resulting wave motion is clear and Figure 3.7 exhibits wave reflection. It is interesting, also, to note that the temperature at $\mathrm{P}_{6}$ increases, until $t_{20}$, at which time it is a maximum, and only then does it proceed to decrease. Figures 3.83.12 show the constant kinetic energy contours $K=0.1,0.05,0.01$, 0.001 at each of the times $t_{5}, t_{10}, t_{15}, t_{20}, t_{25}$, respectively, and indicate the magnitude of the particle velocities at these time steps. 
Other heat transfer concepts can be defined now in the same spirit as above, as follows. A side of the bar is insulated means that the bar particles cannot transfer energy across this side of the bar to particles outside the bar, while melting is the result of adding a sufficient quantity of heat so that various particle velocities attain sufficient magnitude so as to break the bonding effect of (2.4). 


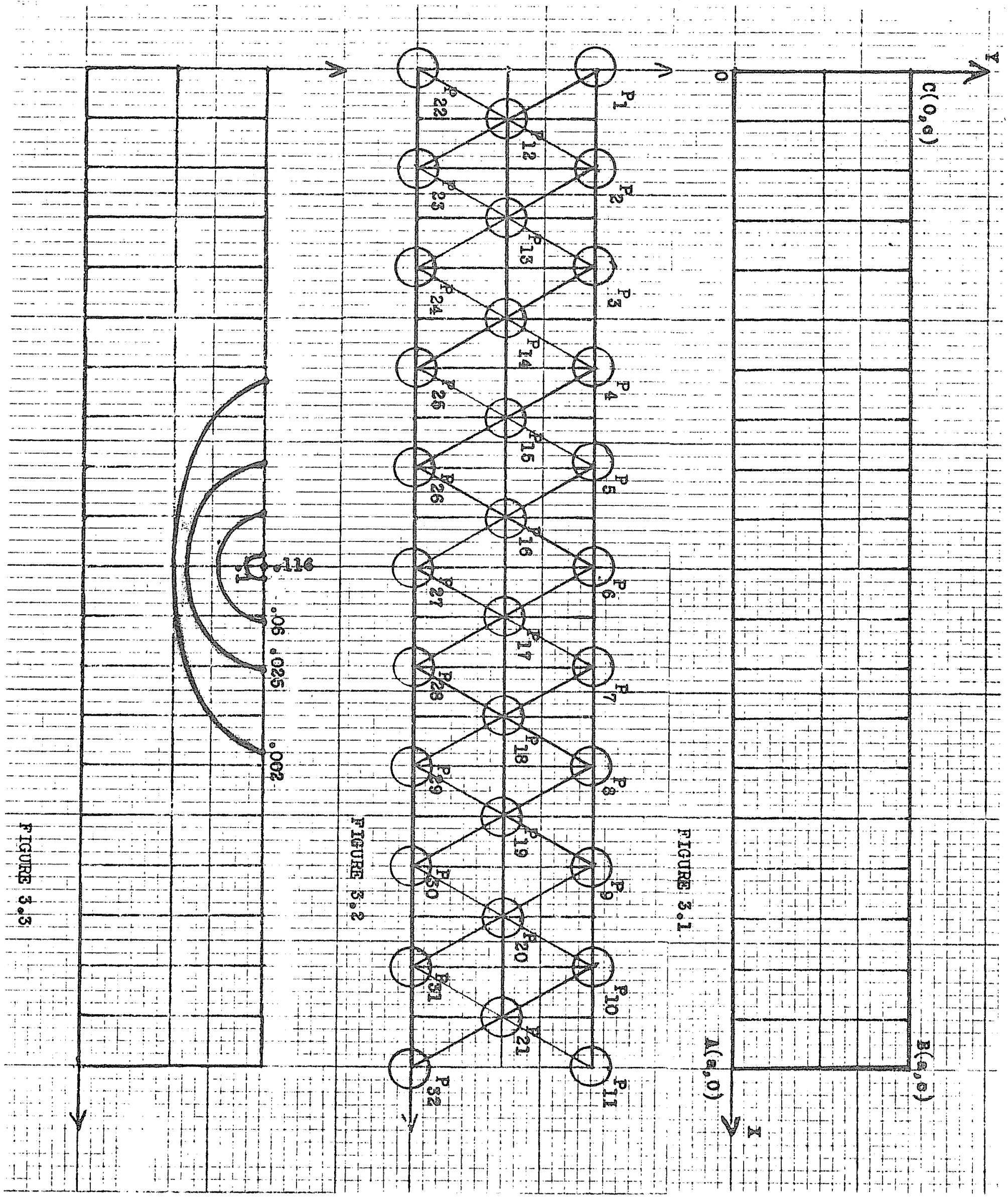




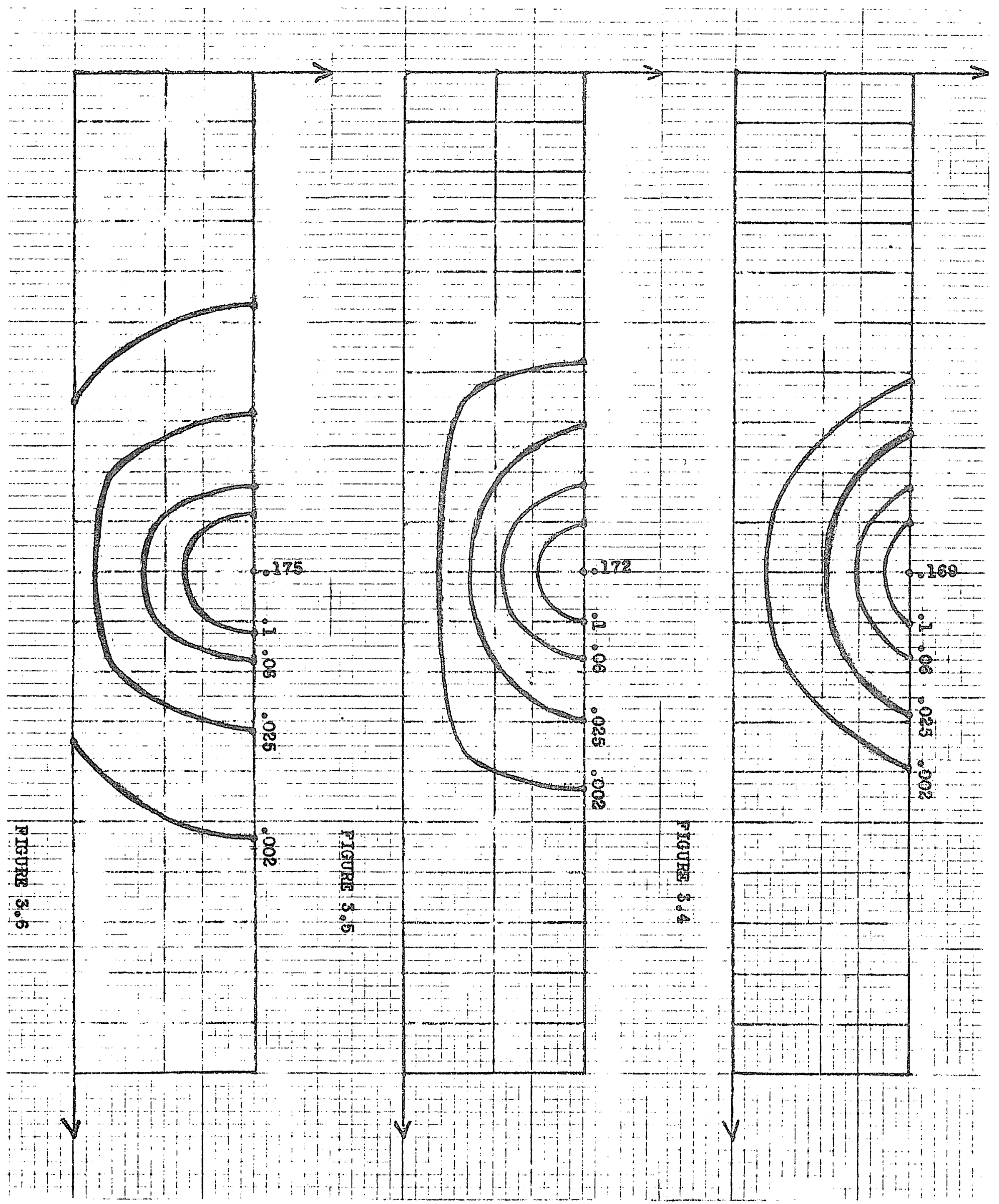


12

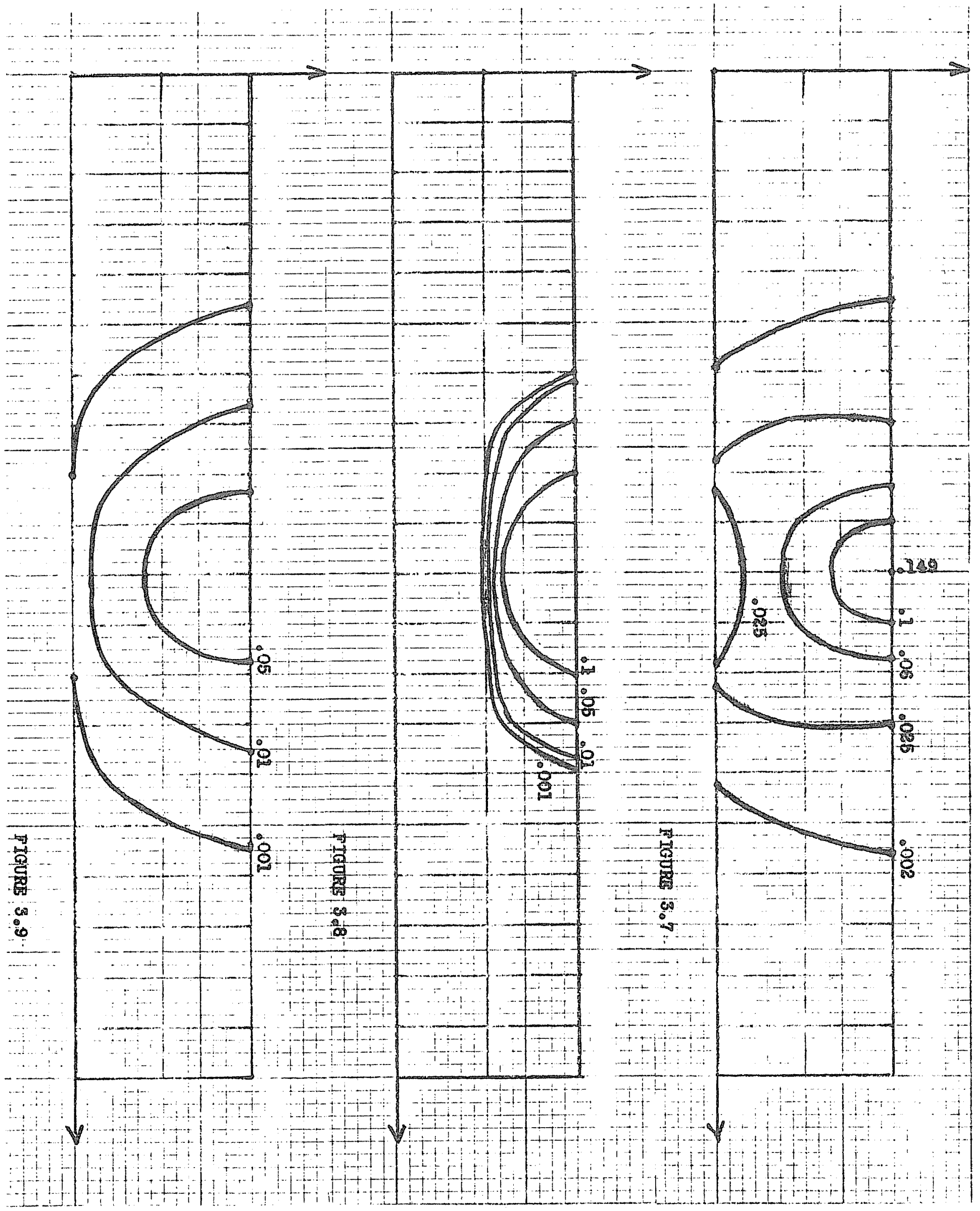




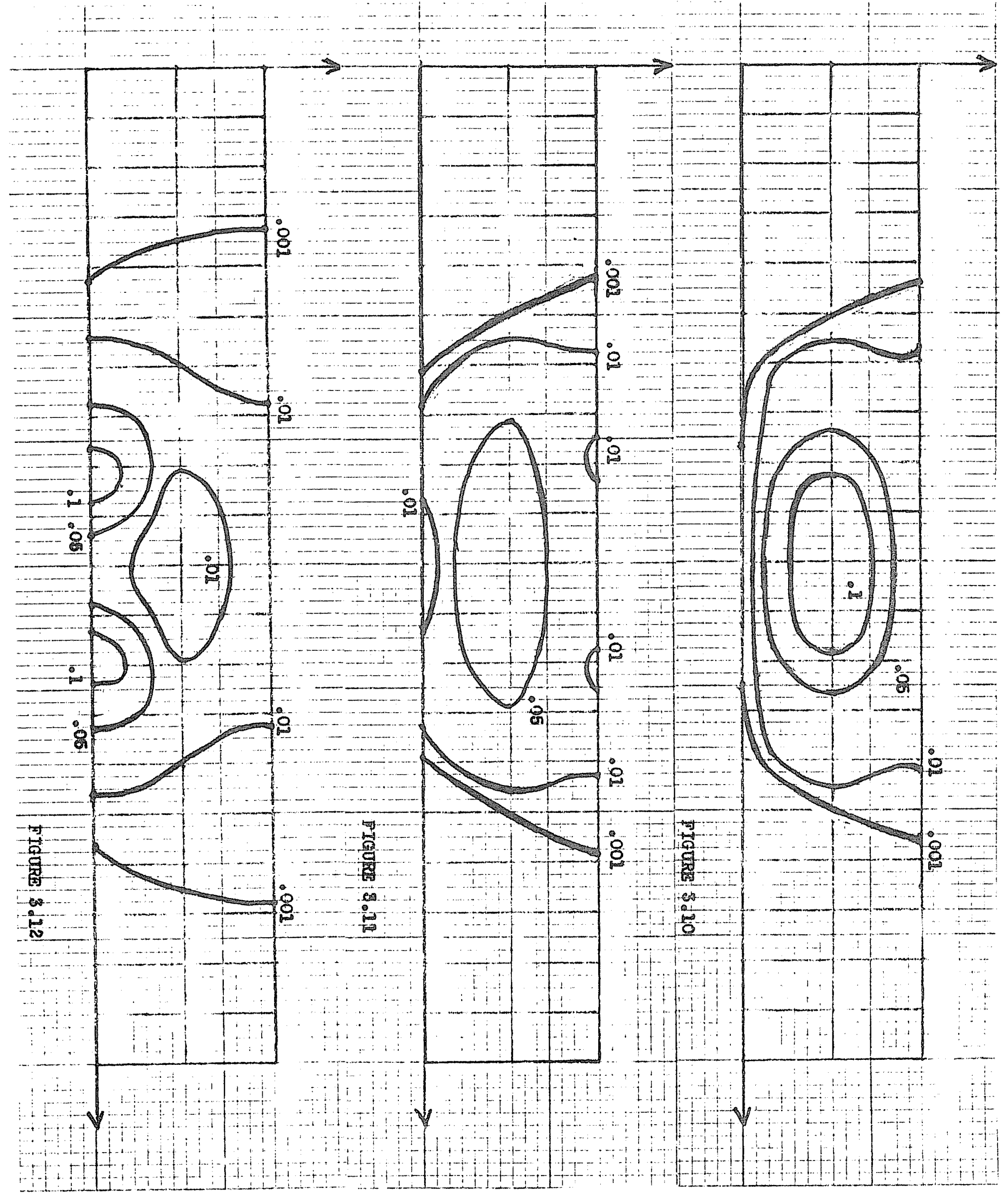




\section{Oscillation of an Elastic Bar}

Next, let us develop the basic concepts of discrete elasticity by concentrating on the vibration of an elastic bar. 'The problem is formulated physically as follows. Let the region bounded by rectangle $0 A B C$, as shown in Figure 3.1, represent a bar which can be deformed, and which, after deformation, tends to return to its original shape. The problem is to describe the motion of such a bar after the external force, which has deformed the bar, is removed. Equivalently, the problem is to describe the motion of an elastic bar after release from a position of tension.

Our discrete approach proceeds as follows. The given region is first subdivided into triangular building blocks. Then, deformation results in the compression of certain particles and the stretching apart of others. Release from a position of deformation, or tension, results, by $(2.4)$, in repulsion between each pair of particles which have been compressed and attraction between each pair which have been stretched, the net effect being the motion of the bar.

As a particular example, let $m_{i} \equiv 1, \alpha=7, \beta=10, p=425, q=1000$, and $\Delta t=.025$. From (3.3), $r=1.52254$. Consider, for variety, the thirty particle bar which results by deleting $P_{11}$ and $P_{32}$ from the configuration of Figure 3.2. The particles $P_{1}, P_{12}$, and $P_{22}$, whose respective coordinates are $(0,2.63711),(.76127,1.31855)$, and $(0,0)$, 
are to be held fixed throughout. In order to obtain an initial position of tension like that shown in Figure $4.1 \mathrm{a}$, first set $\mathrm{P}_{13}, \mathrm{P}_{14}, \mathrm{P}_{15}$, $P_{16}, P_{17}, P_{18}, P_{19}, P_{20}$ and $P_{21}$ at $(2.28357,1.29198)$, (3.80588, $1.26541),(5.32632,1.18573),(6.84052,1.02658),(8.33992, .76219)$, $(9.81058, .36813),(11.23199,-.17750),(12.57631,-.89228)$, and (13.80807, -1.78721$)$, respectively. Any two consecutive points $\mathrm{P}_{\mathrm{k}}$ ' $\mathrm{P}_{k+1}, \mathrm{k}=13,14, \ldots, 20$, are positioned $\mathrm{r}$ units apart. The points $P_{2}-P_{10}$ and $P_{23}-P_{31}$ are then positioned as follows: $P_{k-10}$ and $\mathrm{P}_{\mathrm{k}+11}$ are the two points which are $\mathrm{r}$ units from both $\mathrm{P}_{\mathrm{k}}$ and $\mathrm{P}_{\mathrm{k}+1}$ for each of $k=12,13, \ldots, 20$. Each consecutive pair of points in the $\mathrm{P}_{2}-\mathrm{P}_{10}$ set is then separated by a distance greater than $r$, while each consecutive pair of points in the $\mathrm{P}_{23}-\mathrm{P}_{31}$ set is separated by a distance less than $r$. Thus, the points $P_{2}-P_{10}$ are in a stretched position, while the points $\mathrm{P}_{23}-\mathrm{P}_{31}$ are compressed.

From the initial position of tension shown in Figure $4.1 \mathrm{a}$, the oscillatory motion of the bar is determined from (2.1)-(2.4) with all initial velocities set as $\overrightarrow{0}$. The upward swing of the bar was plotted automatically at every ten time steps and is shown in Figure 4.1 amw from $t_{0}$ to $t_{220}$. It is of interest to note that as the bar moves, each row of particles exhibits wave oscillation and reflection. 
Fig. 4.1
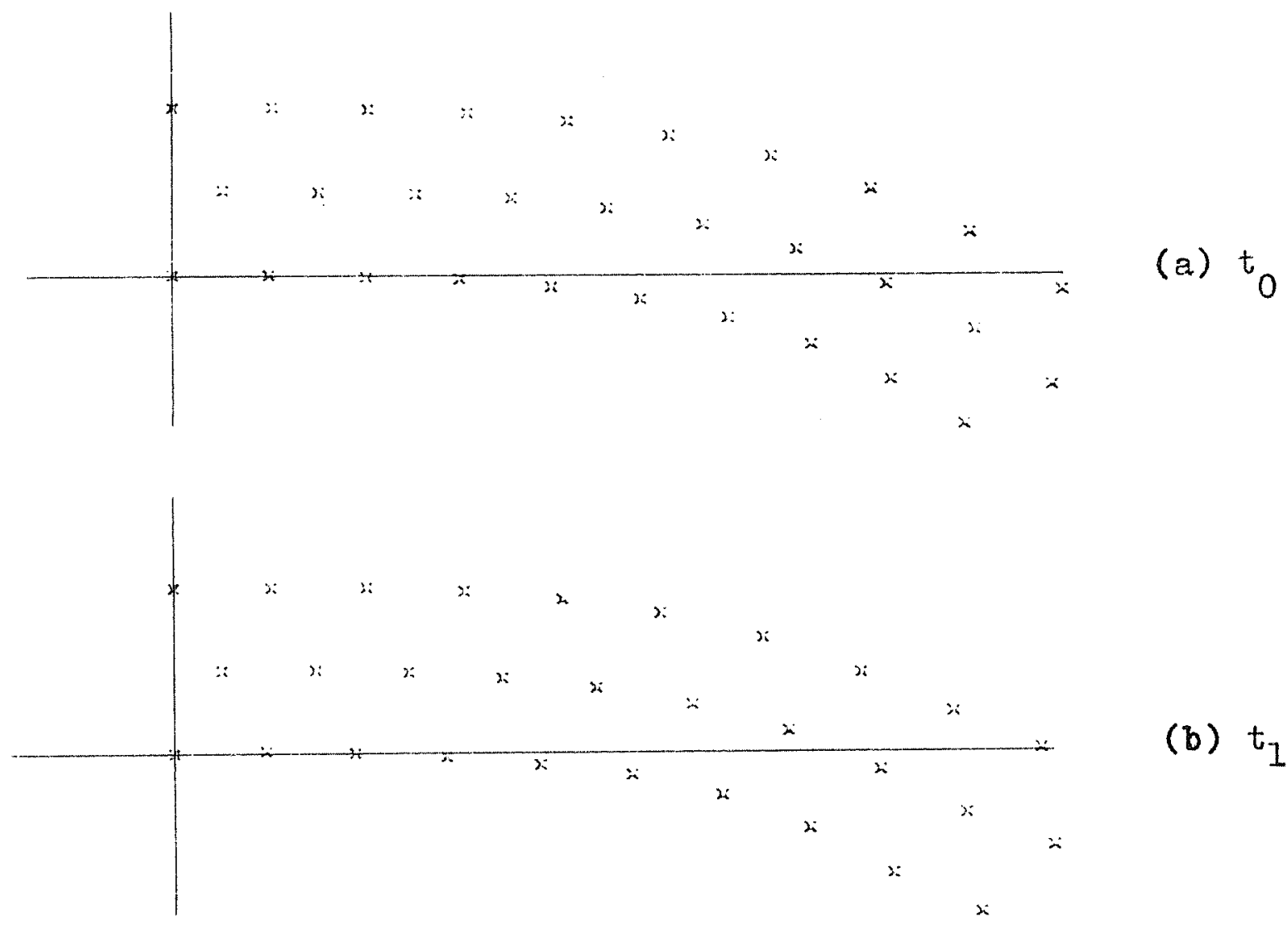

(b) $t_{10}$

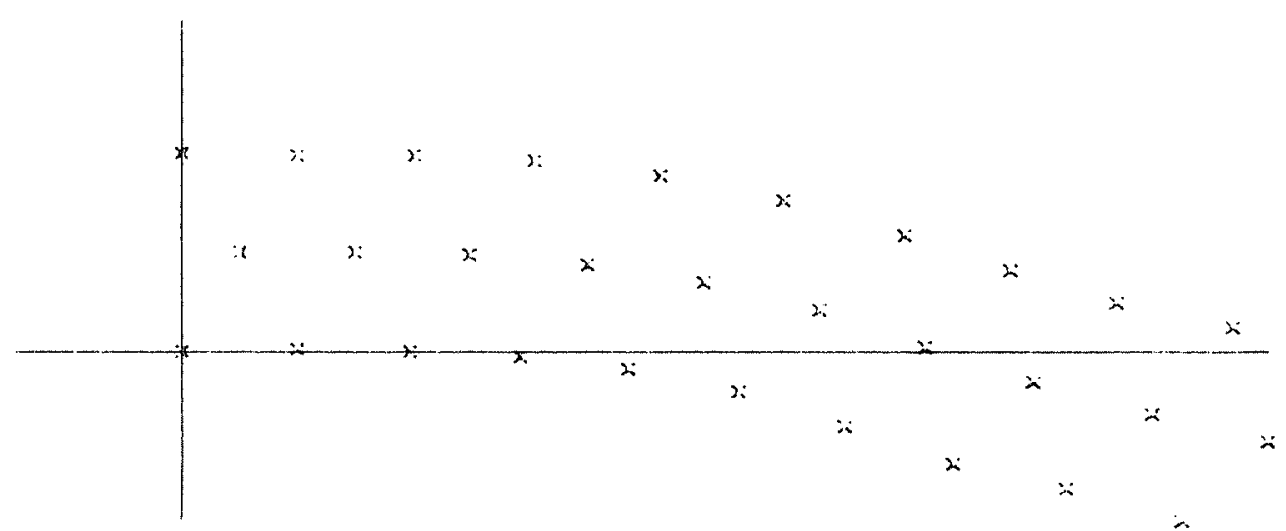

(c) $t_{20}$

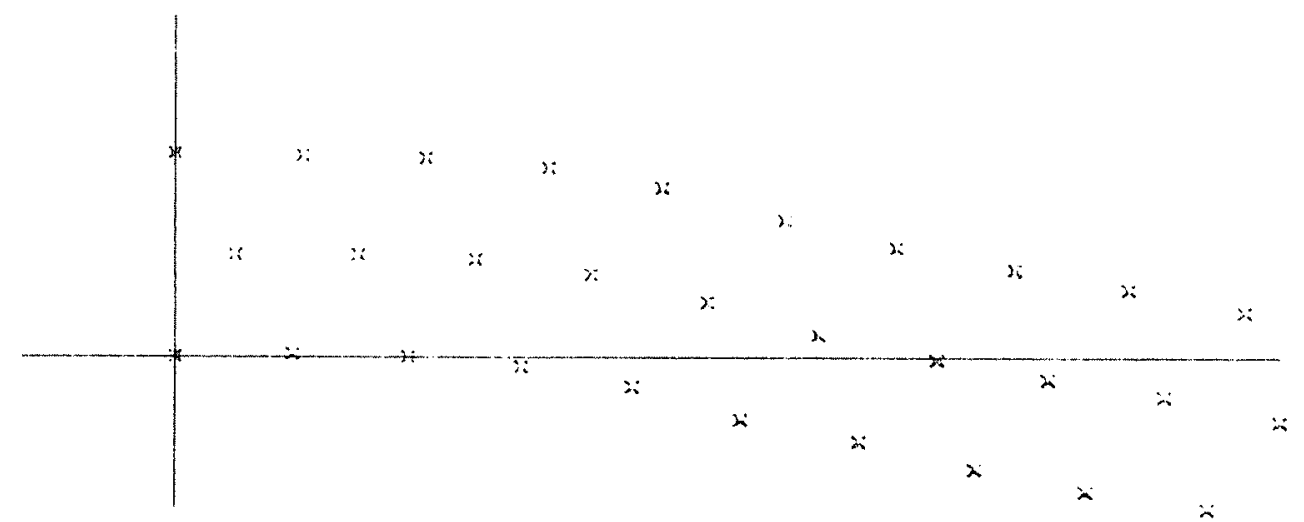

(d) $t_{30}$ 


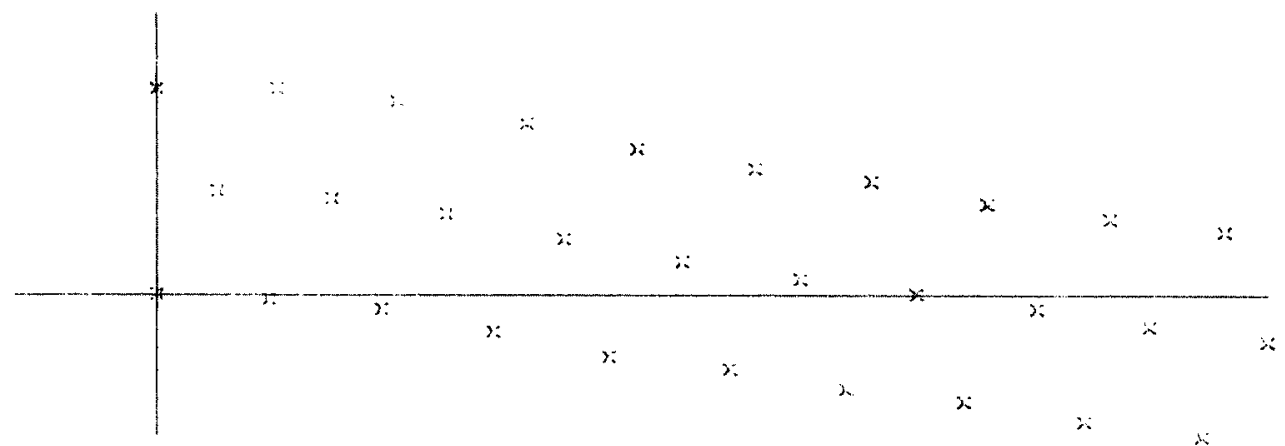

(e) $t_{40}$

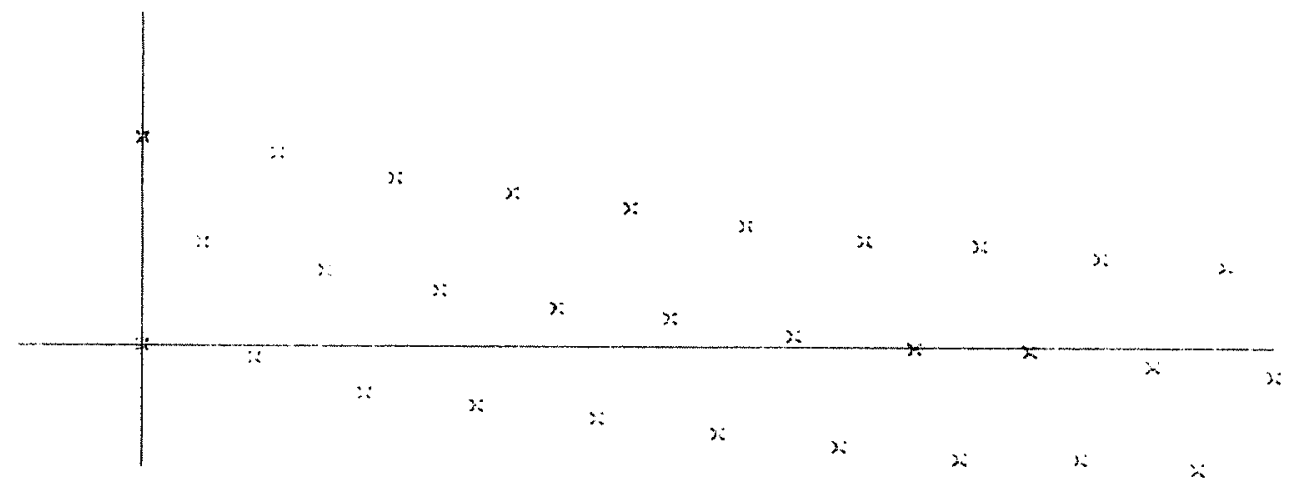

(f) $t_{50}$

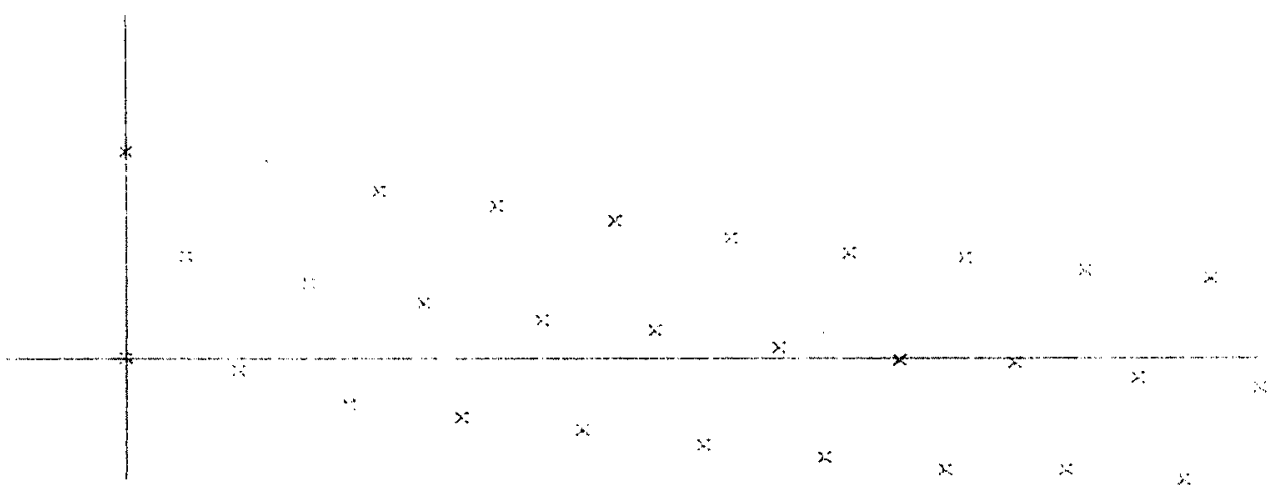

(g) $t_{60}$

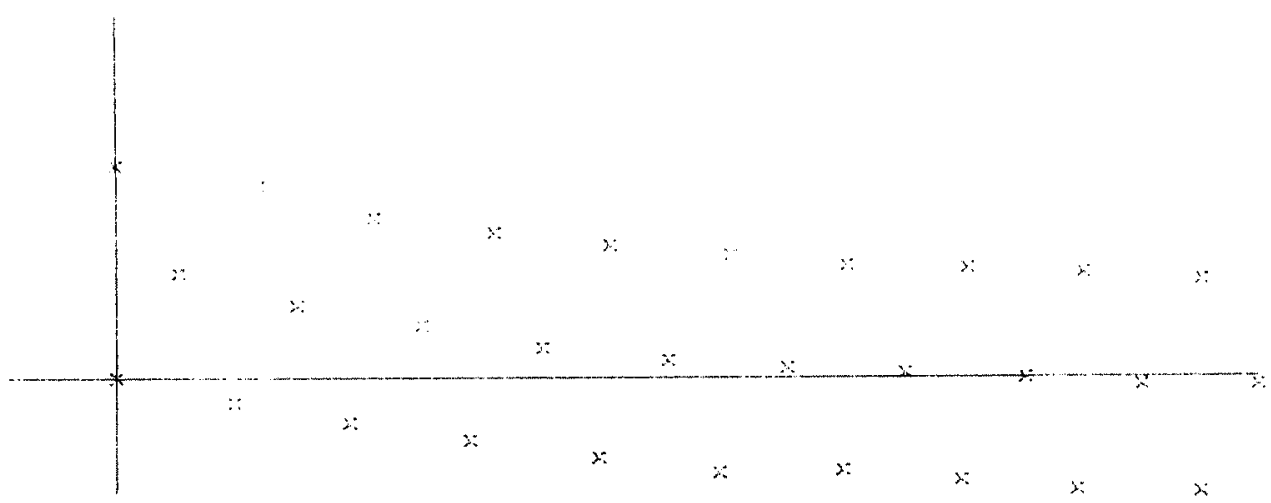

(h) $t_{70}$ 


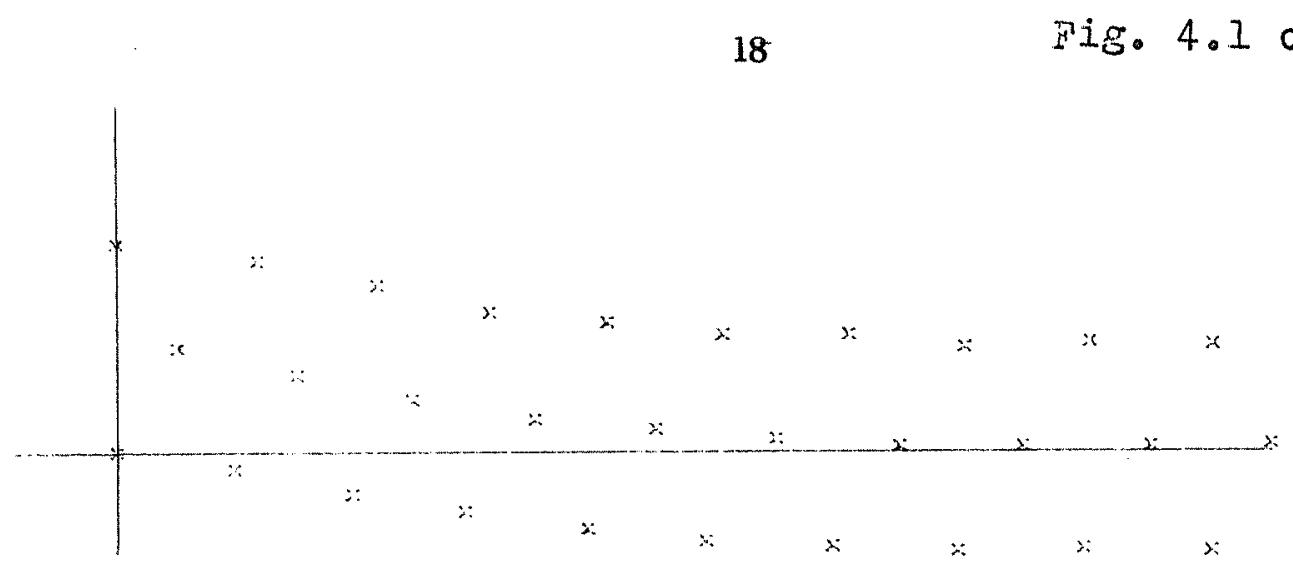

(i) $t_{80}$

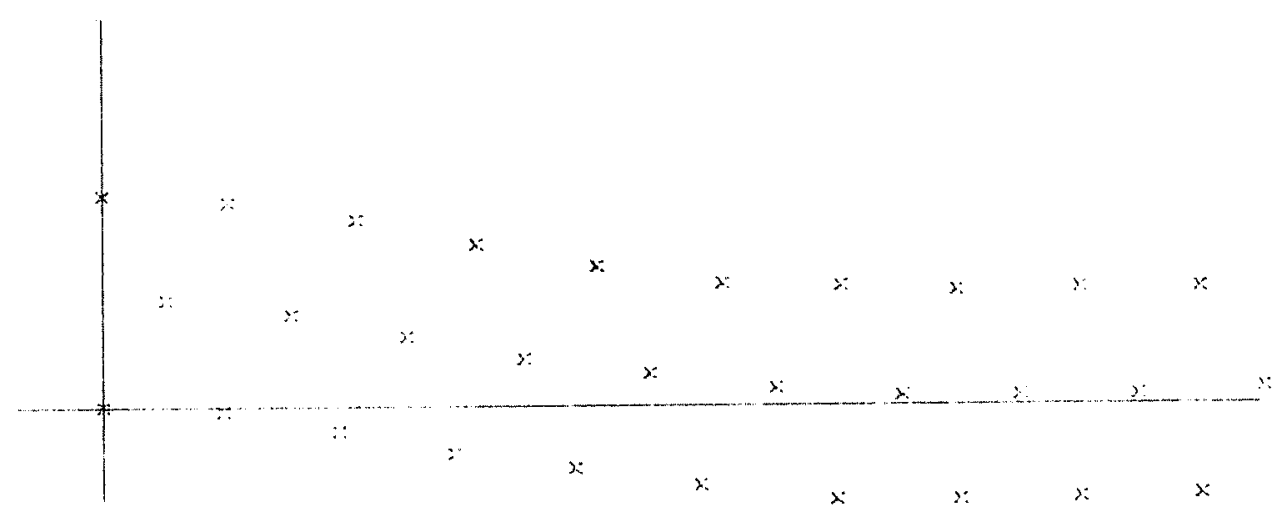

(j) $t_{90}$

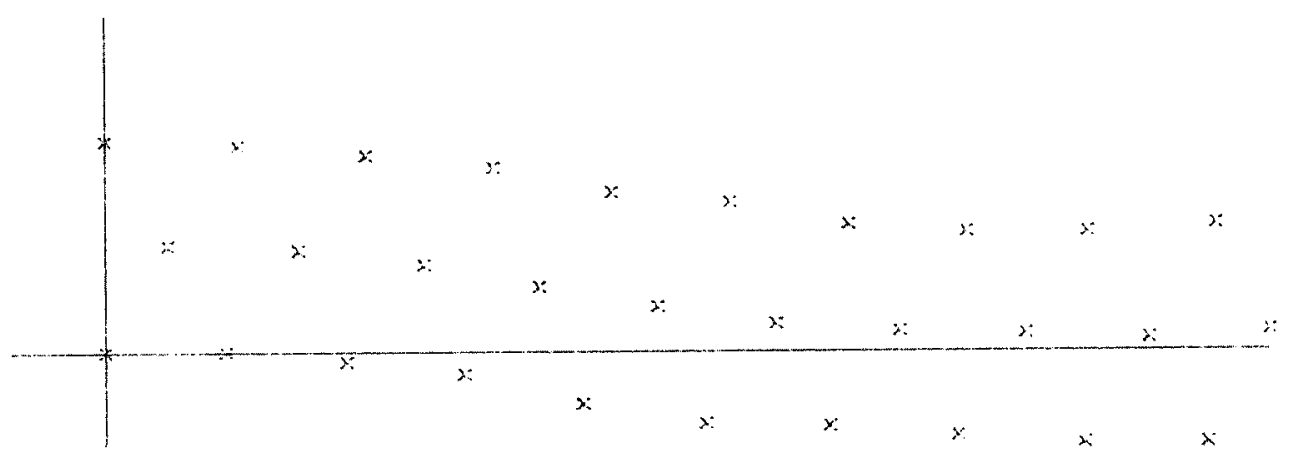

(k) $t_{100}$

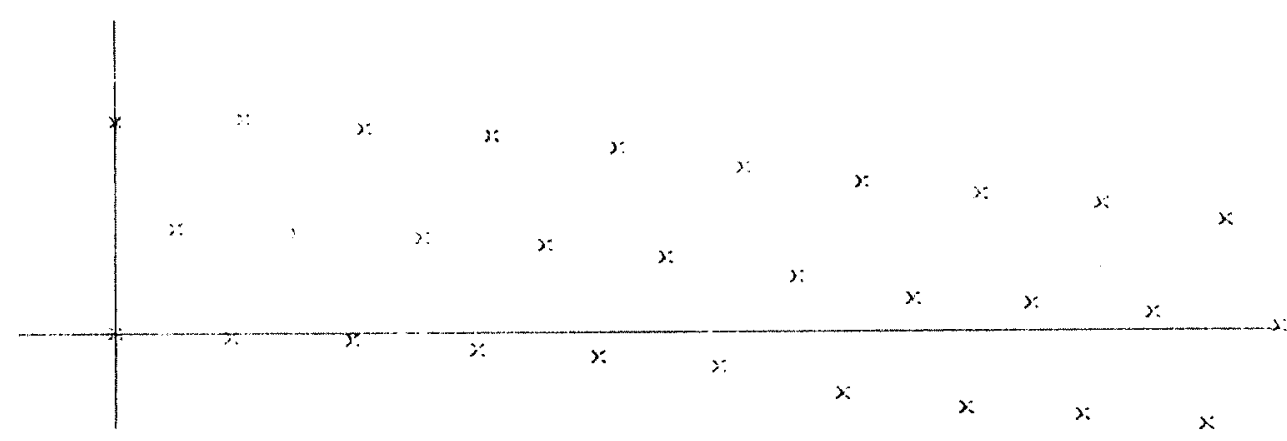

(1) $t_{110}$ 


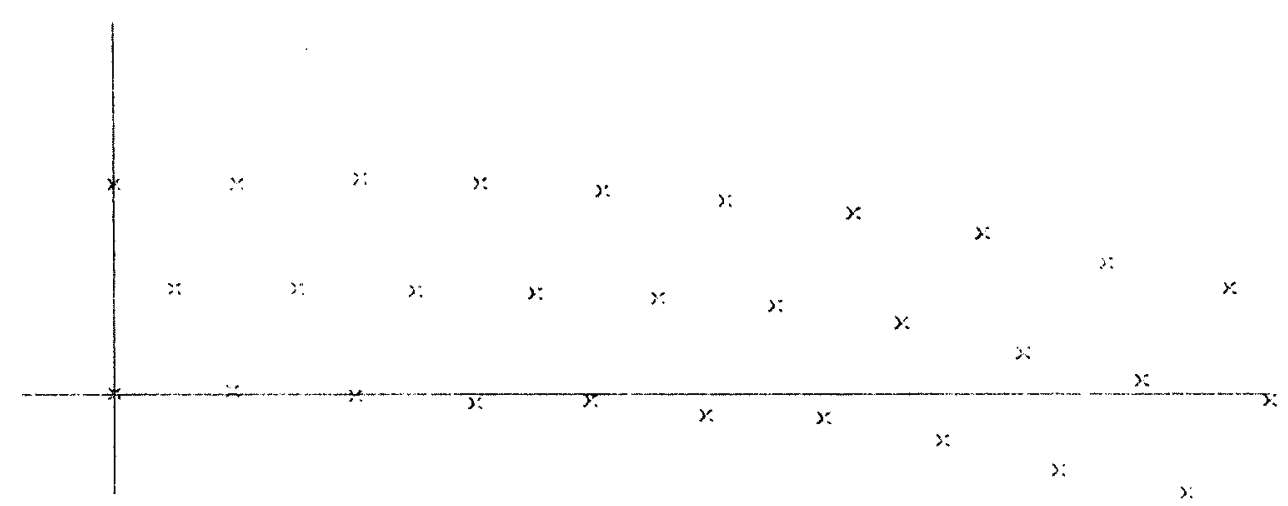

\section{(m) $t_{120}$}

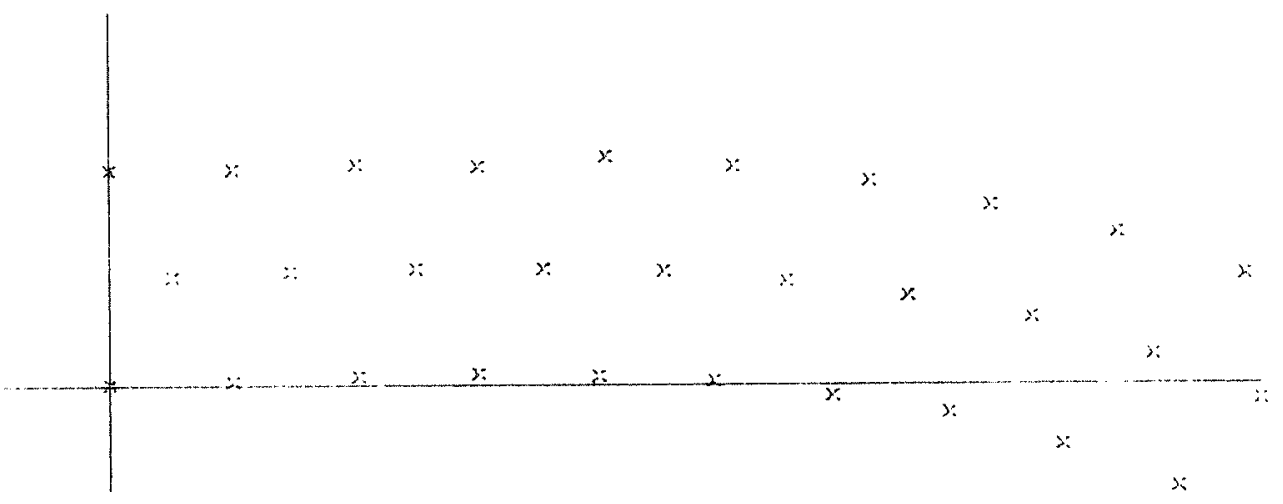

(n) $t_{130}$

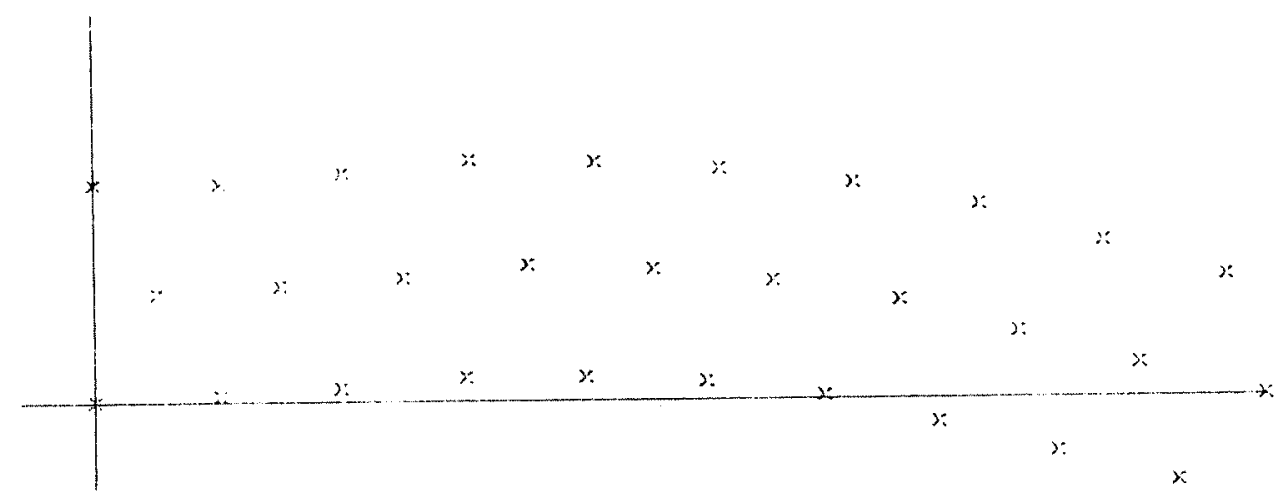

(o) $t_{140}$

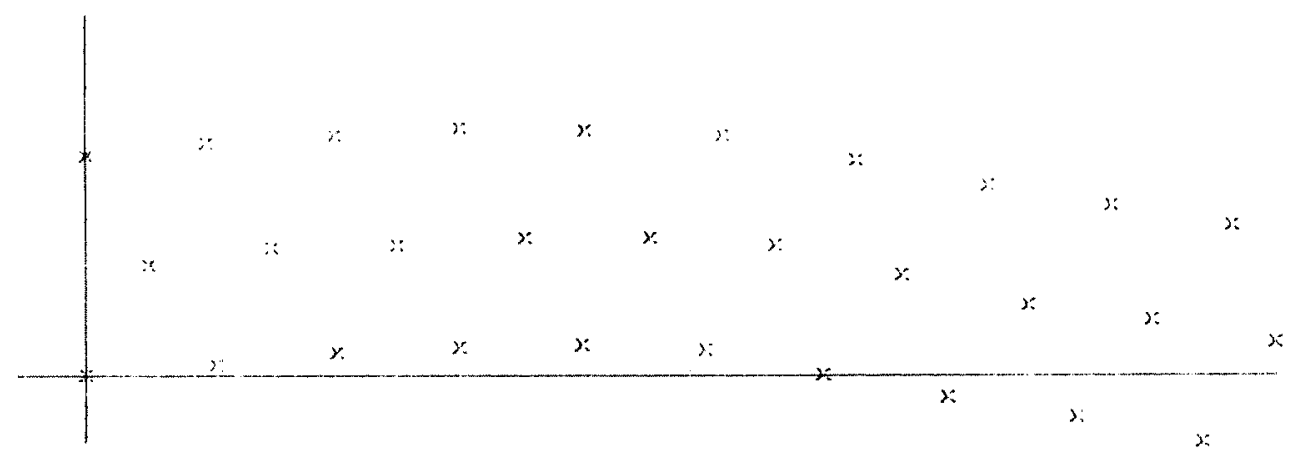

(p) $t_{150}$ 
20

Fig. 4.1 cont.

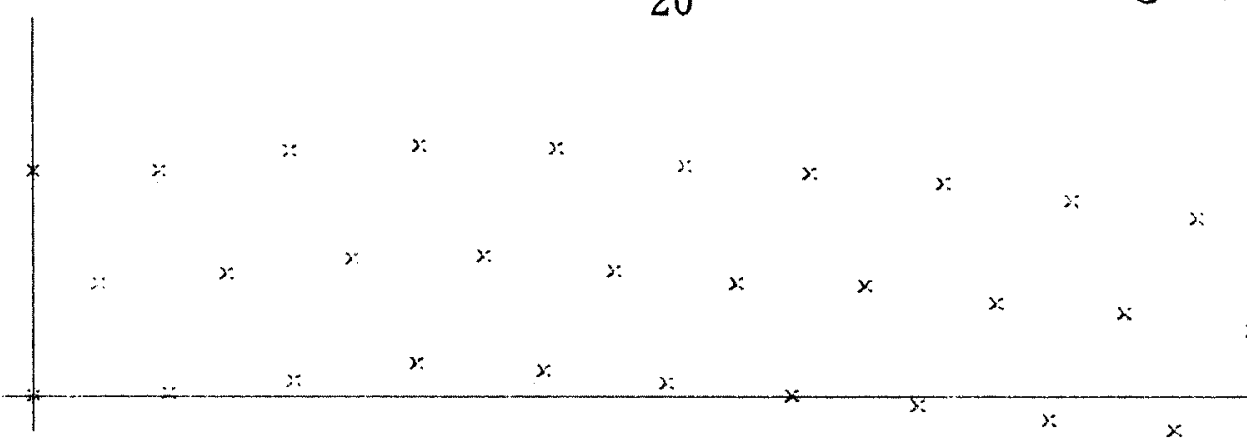

(q) $t_{160}$

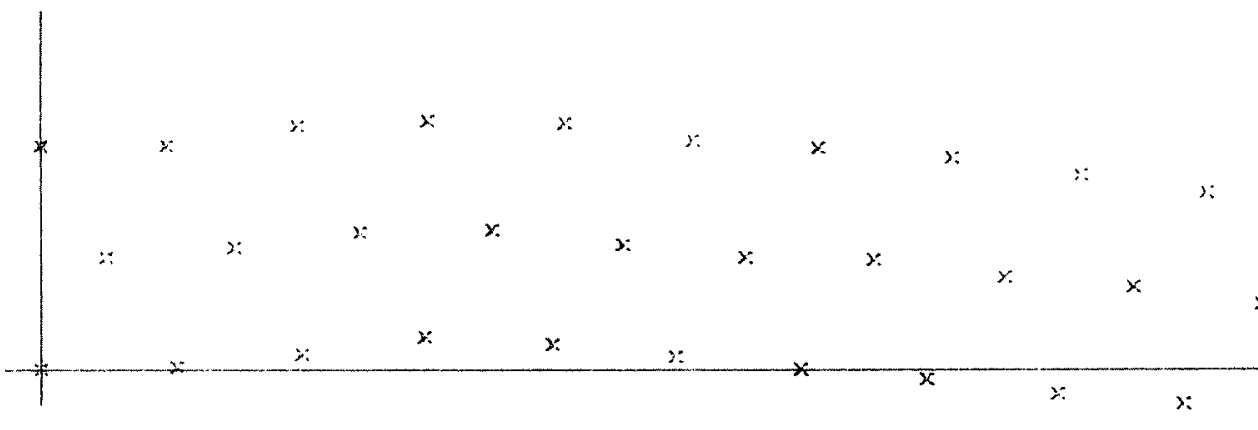

(r) $t_{170}$

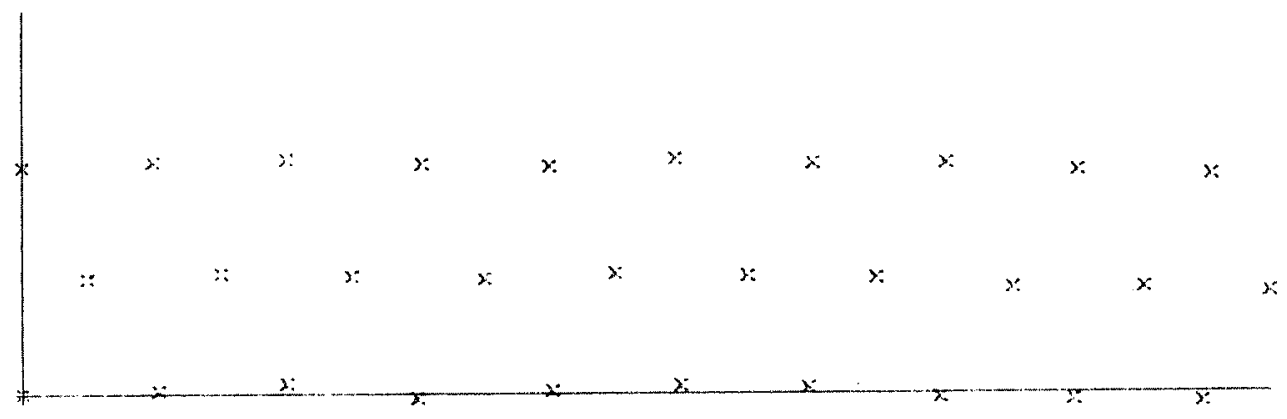

(s) $t_{180}$

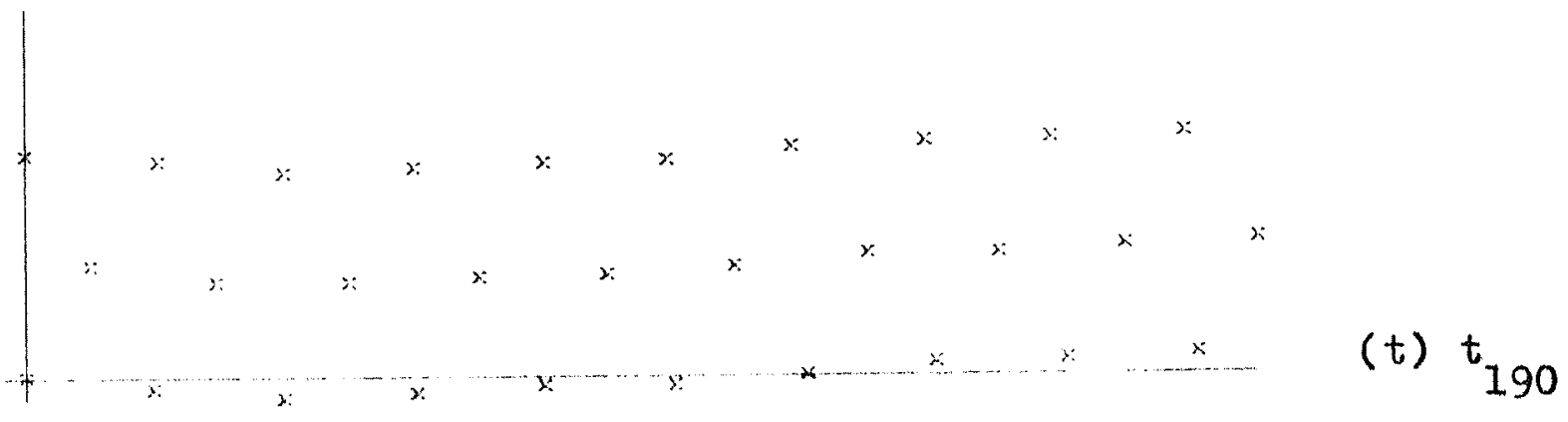




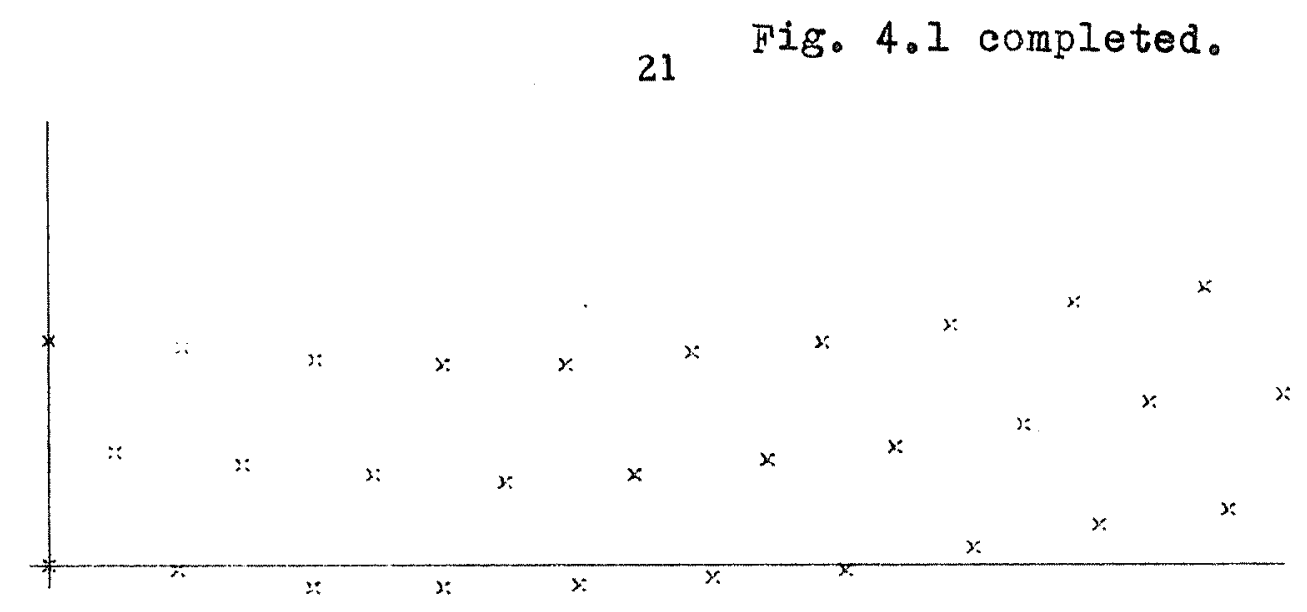

(u) $t_{200}$

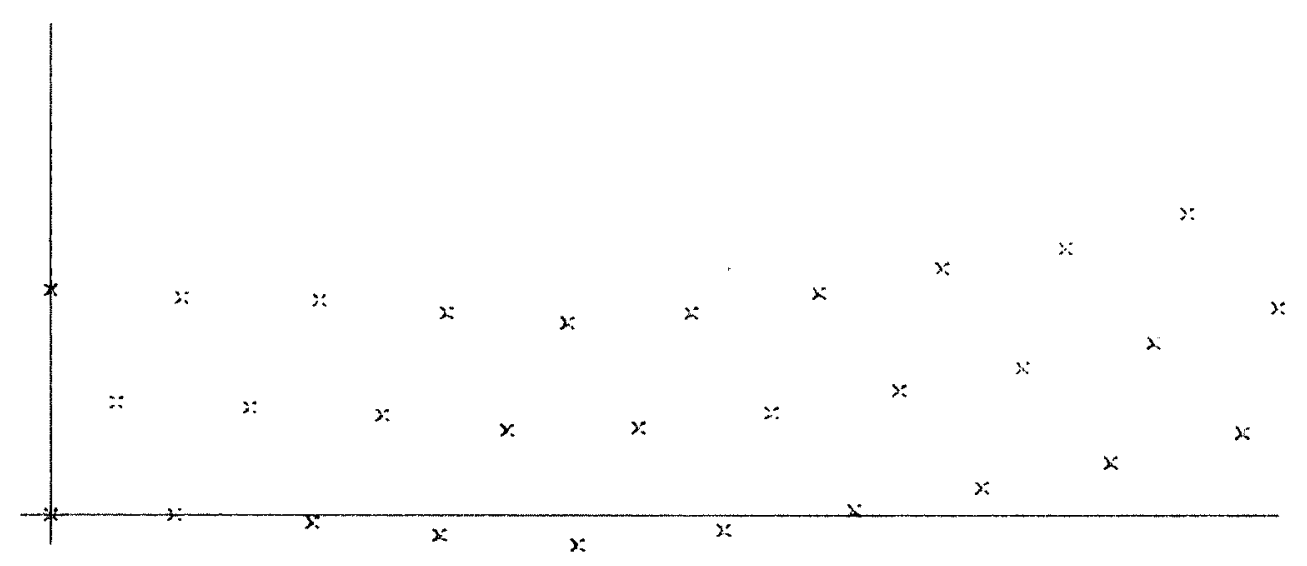

(v) $t_{210}$

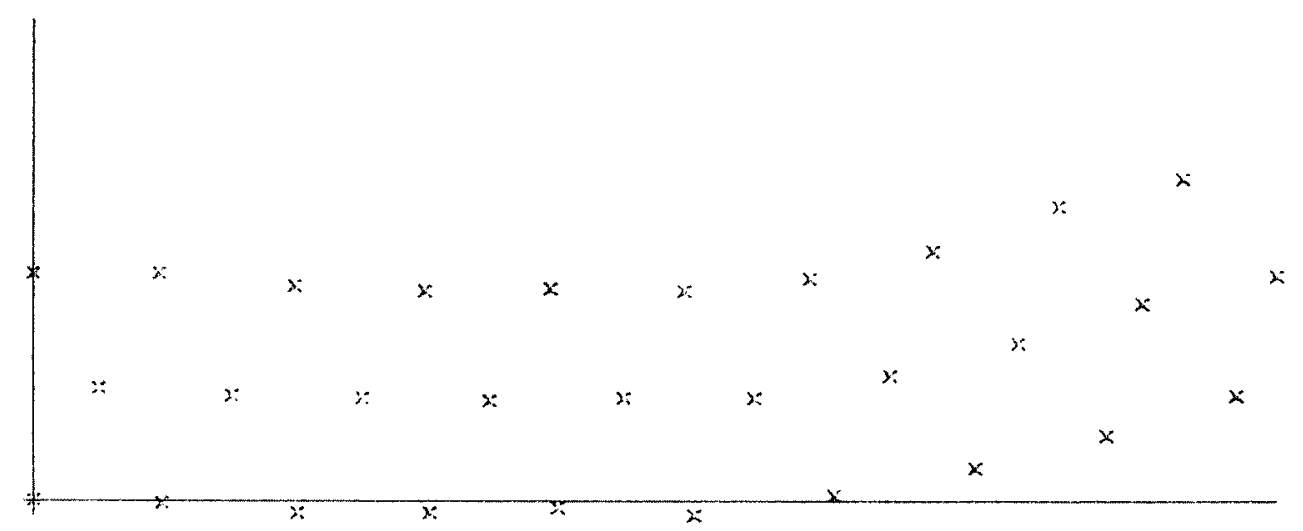

(w) $t_{220}$ 


\section{Remarks}

A limited number of other examples were run, and these indicated that square building blocks were less stable than triangular ones, while the choices $\alpha=2, \beta=5$ and $\alpha=7, \beta=13$ were less viable than $\alpha=7, \beta=10$. Generally speaking, any choice $p>q$ resulted in increased oscillations so that, for example, for the elastic bar model of Section 4 , the choice $p=3, q=1$ required a refinement of time step to $\Delta t=10^{-3}$ in order to study the resulting oscillations. The major handicap in all the computer examples run was the lack of adequate funding to enable the study of models with large numbers of particles. Finally, it should be noted that the writer feels that varying $\alpha$, $\beta, p$ and $q$ in computer models with large numbers of particles will enable the researcher to produce viable computer models and to derive insight into the actual parameter values for various physical solids. 


\section{$\underline{\text { References }}$}

1. J. Douglas, Jr., "A Survey of Numerical Methods for Parabolic Differential Equations," in Advances in Computers, vol. 2, Academic Press, N. Y., 1961, pp. 1-55.

2. R. P. Feynman, R. B. Leighton, and M. Sands, The Feynman Lectures on Physics, Addison-Wesley, Reading, Mass., 1964.

3. A. Friedman, Partial Differential Equations of Parabolic Type, Prentice-Hall, Englewood Cliffs, N. J., 1964.

4. D. Greenspan, Lectures on the Numerical Solution of Linear, Singular, and Nonlinear Differential Equations, Prentice-Hall, Englewood Cliffs, N. J., 1968.

5. "New Forms of Discrete Mechanics," Kybernetes, $1,1972, \mathrm{pp} .87-101$.

6. "An Algebraic, Energy Conserving Formulation of Classical Molecular and Newtonian n-Body Interaction, " to appear in Bull. Amer. Math. Soc.

7. S. T. Jones, "FORTRAN program for discrete conductive heat transfer, " Appendix, TR\#164, Department of Computer Sciences, Univ, of Wis., Madison, 1972.

8. C. Kittel, Introduction to Solid State Physics, 4th Ed., Wiley, N. Y., 1971 .

9. P. G. Klemens, "Theory of Thermal Conductivity of Solids," in Thermal Conductivity I, Academic Press, N. Y., 1969, pp. 1-68.

10. S. S. Kutateladze and V. M. Borishanskii, A Concise Encyclopedia of Heat Transfer, Pergamon, N. Y., 1966.

11. V. V. Novozhilov, Foundations of the Nonlinear Theory of Elasticity, Graylock, Rochester, N. Y., 1953.

12. W. Prager, Introduction to the Mechanics of Continua, Ginn, Boston, 1961 . 
13. S. Timoshenko and J. Gere, Theory of Elastic Stability, McGrawHill, N. Y. , 1961 .

14. S. Timoshenko and S. Woinowsky-Krieger, Theory of Plates and Shells, McGraw-Hill, N. Y., 1959. 
APPENDIX: FORTRAN Program for Discrete Conductive Heat Transfer by S.T. Jones

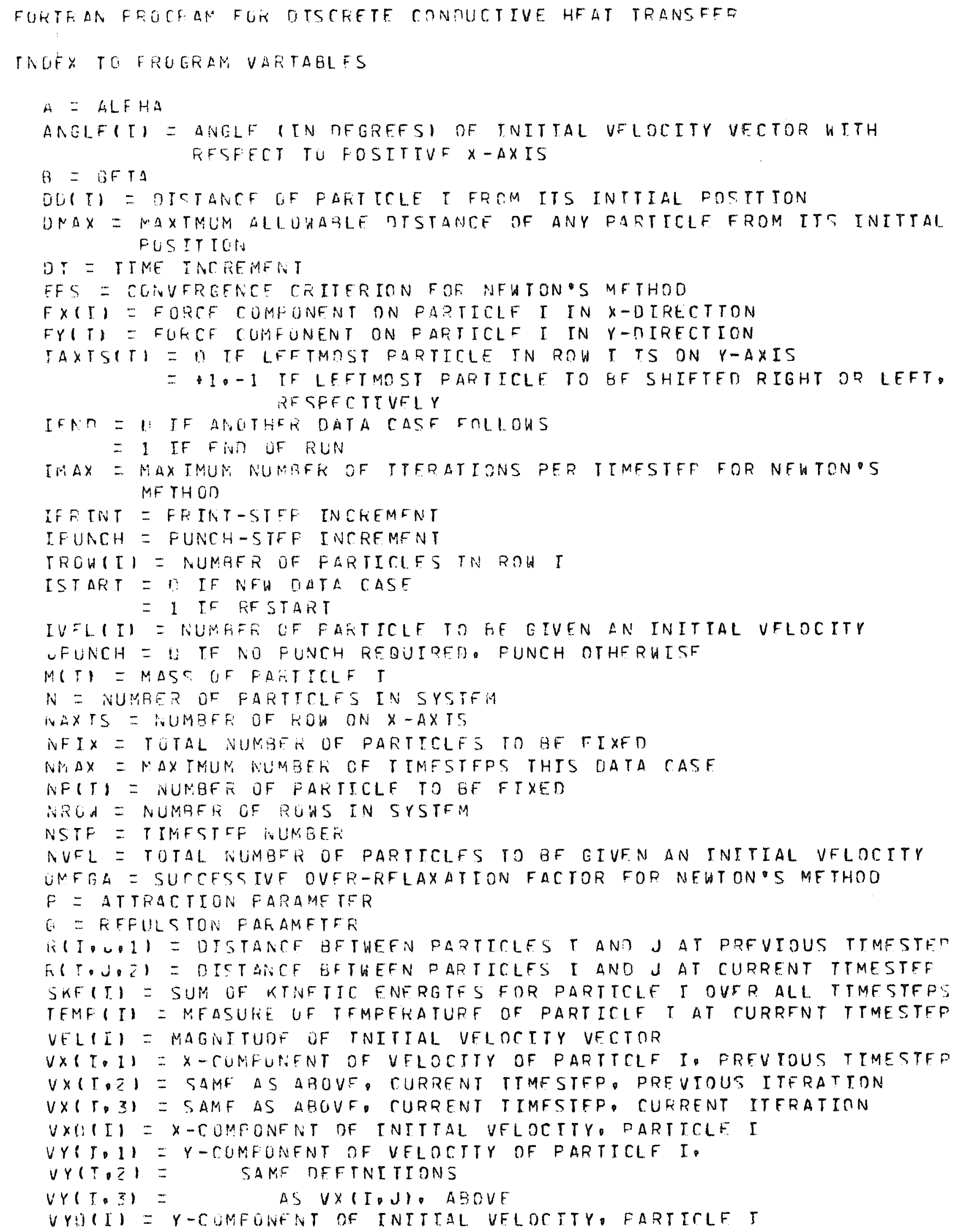




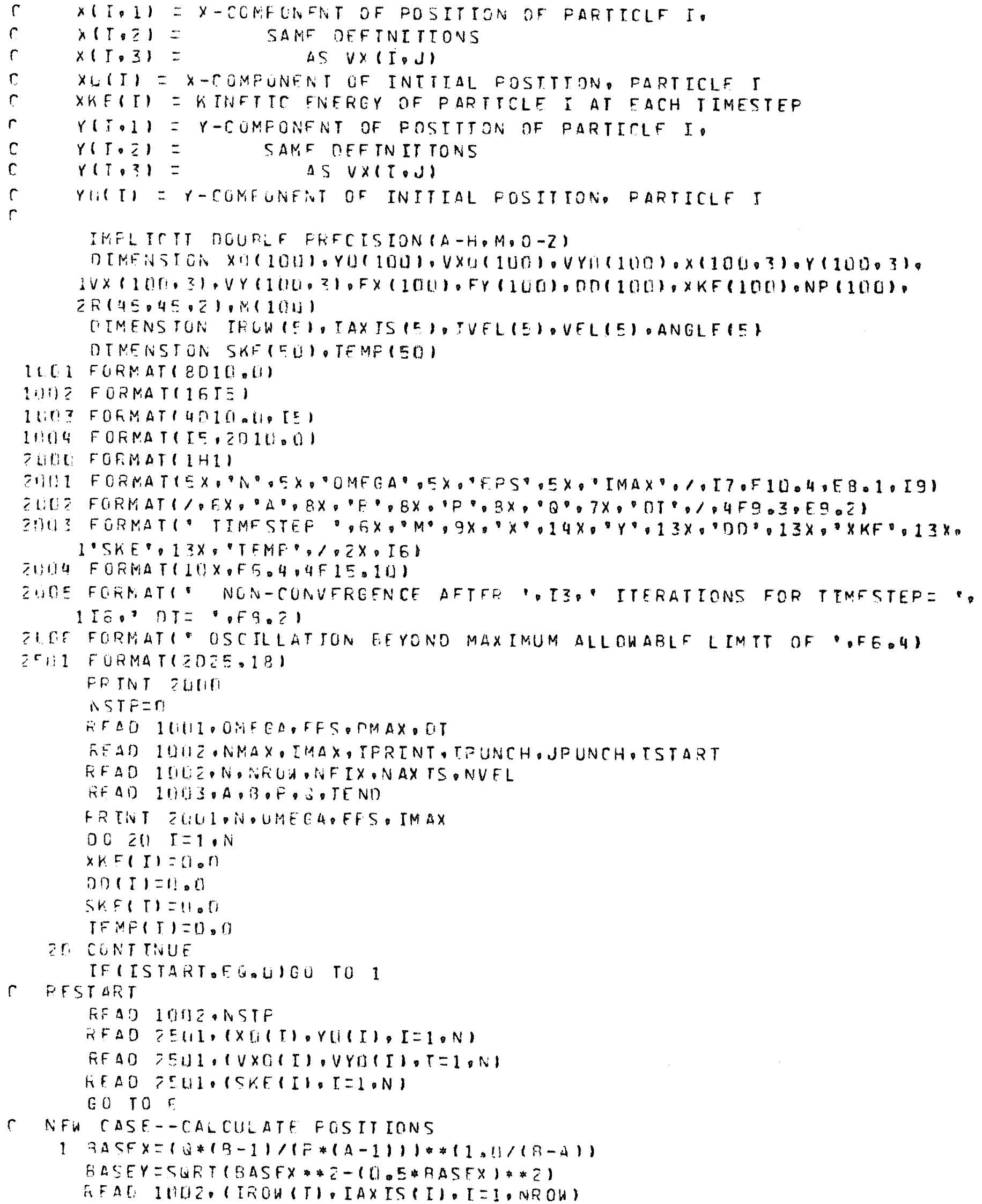




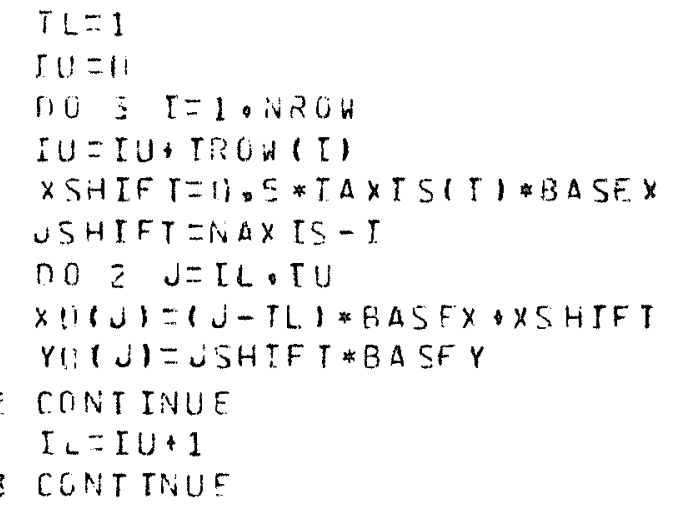

C VE TASF--CALCULATE VFLOCITIFS

$11100 \quad 4 \quad T=1$, iv

$\checkmark \times[1)(I=0.0$

VYCIIII)

4 CONTINUF

IFINVEL FG. III GO TO E

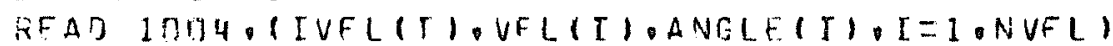

$F T=3.141502 F+3580793240000$

RAD $=F T / 130.1$

$005 T=1 . N V F L$

$u=T V F L I I$

THFTA=ARELF(I) HAC

VXO(J)=VFL(I) COSITHFTA)

VYCIJIEVEL(I) S INITHFTAI

r. CONTINUF

F. $[$ iO $7 T=1 \cdot \mathrm{H}$

$N(T)=1 \cdot 0$

7 CONT TNUF

$C N W=1, H-O M E G A$

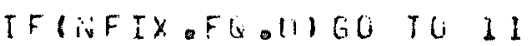

FFAD $10 U Z$, NF(I),I $=1$, NFI $X)$

11 FFINT ZUDZOA.P. OU.DT

$T=0 \cdot 1)$

กTE $=[T / Z$ Q

FRTNT ZIITSONSTP

חO $3 \mathrm{C} \quad \mathrm{T}=1 \cdot \mathrm{N}$

FFTNT ZIIT4.M(T).XOTI) YOTT).ODIT).XKFTT)

?I CONTTNUE

$r$ TFEEIFY INITTAL GUESS FOR NEUTONOS ITERATTON AT FIRST TIMESTEP

ก $40 \quad T=1 \cdot N$

$\times(1,3)=x[1,1$,

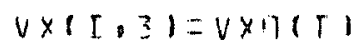

$Y(T, 3)=Y \|(I)$

41] VYID $31=V Y \cap 1 T)$

CALL RCALC

C UFDATF FOSTTIUIVSUFLUCITIESOTISTANCFS FOR ALL TTMFSTFPS

4 E NSTFENSTF+1

$T=T+0 T$

OC EU T=1. i

$x([, 1)=x(I, 3)$

$V \times([01)=V \times(T, 3)$

$Y(T .1)=Y(T . ?)$ 


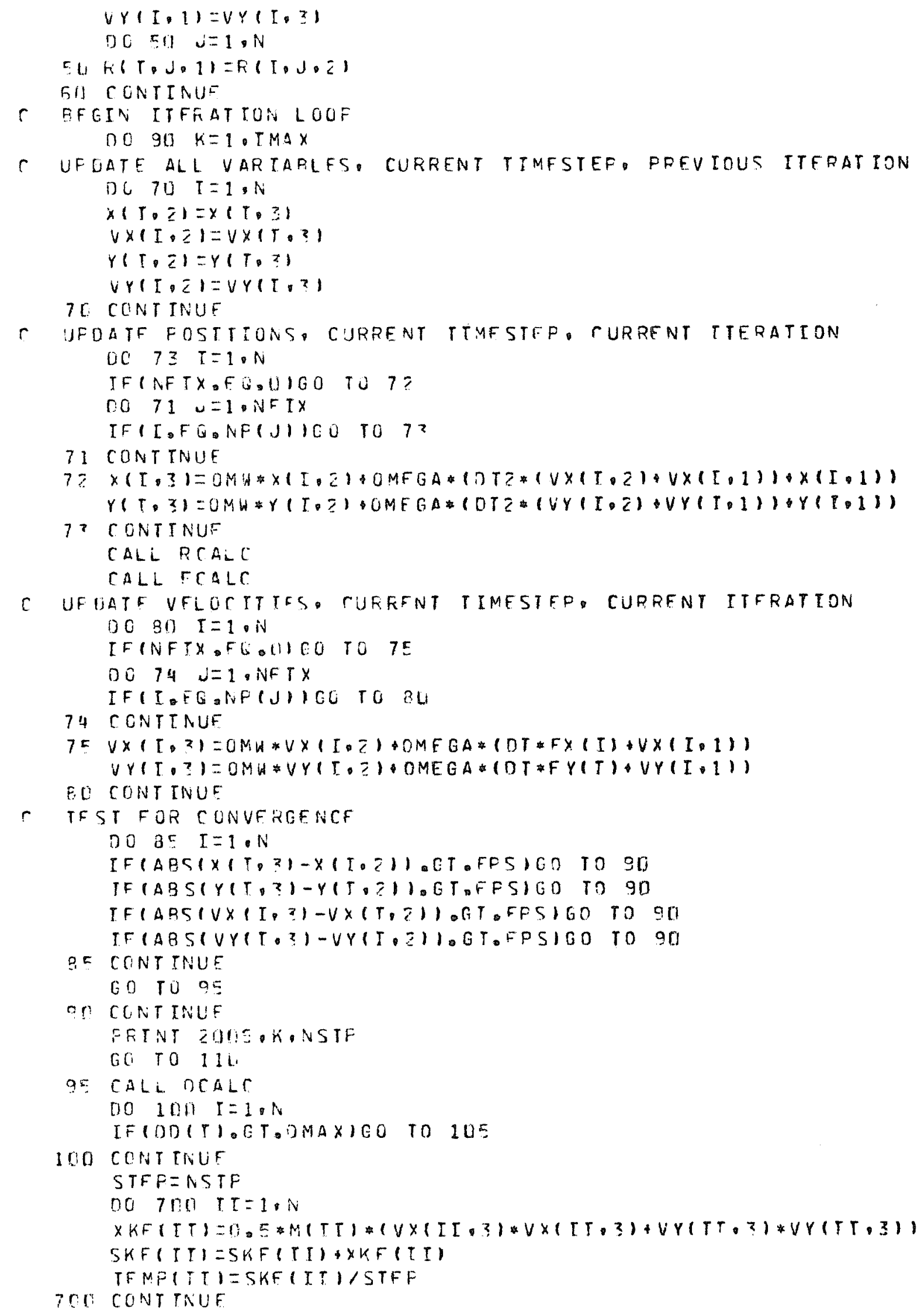


TFIMONCNSTF. LFRTNTI,NF.0IGO TO 1G?

IFIUPUNCH, FQ 11160 TO 102

IF (MODT INSTF. TFUMTH).NF.01GO TO 102

WETTFI 1. 1OOEINSTF

DC 1 L 1 I $I=1$ ON

WRTTE( $1, \geq 5 U 1) \times(T, 3), Y(I, 3)$

1 E CONTINUF

$00 \quad 15 ? \quad I=1,4$

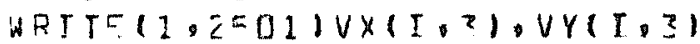

LEZ CONTINUE

HFTTF(1, QED1) SKF (II , II $=1, N)$

1 II) CALL OUTF

10? IFINSTF,F日,NMAXIGO TO 110

GO TO

10T: FRTNT ZUITS.DMAX

CALL DUTF

110 IFIIEND,FO.01GO TU 10 STOF

C INTERNAL SUBRUUTTNF TO TOMPUTE DTSTANCFS BFTUEEN FARTICLFS

SURROUTINF FCALC

DO $210 \quad T \mathrm{~T}=1$, iv

IF $1=T I+1$

DO 200 UU:IFI, N

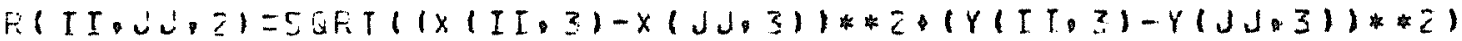

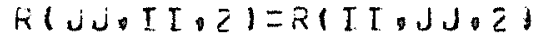

ZLL CONT TNLE

Z10 CONTINUE

RFTURN

r INTERNAL SUBRUUTTNE TO COMFUTF DISTANCF OF PARTTCLF FROM ITS INTTTAL

r FUSITTON

SURFOUTINF DCALC

$00300 \quad I I=I, N$

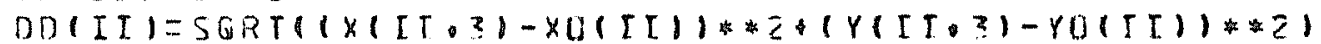

IOI CONTINUE

RF TURN

C TRTERNAL SUBROUTINE TO COMFUTE FORCFS

SURROUTINF. FCALC

I $A=A-1$

I $R=B-1$

DO EDU TI $T=I$, N

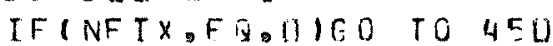

DO 4OO KK=1.NFTX

IFIITOEQ ONPCKKIICO TO 600

HIII CONTLNUE

$450 \quad 5 U M X=0.15$

SUMY $=0.0$

450 OC EER UU $=1, N$

IFIII.FQAJJIEO TO 550

SUMF $=0.0$

SUMO $=0.0$

$R T u=R(T I \circ j J \cdot I 1+R(T I \cdot J J \cdot Z)$

DO ECO $I:=1: I A$

SUMP $=$ SUMF*(R(II,JJ.1)**(IZ-1) $*(R(I I * J) \cdot Z) *(A-(I Z-1)-Z))$

=OT CONT INUF 


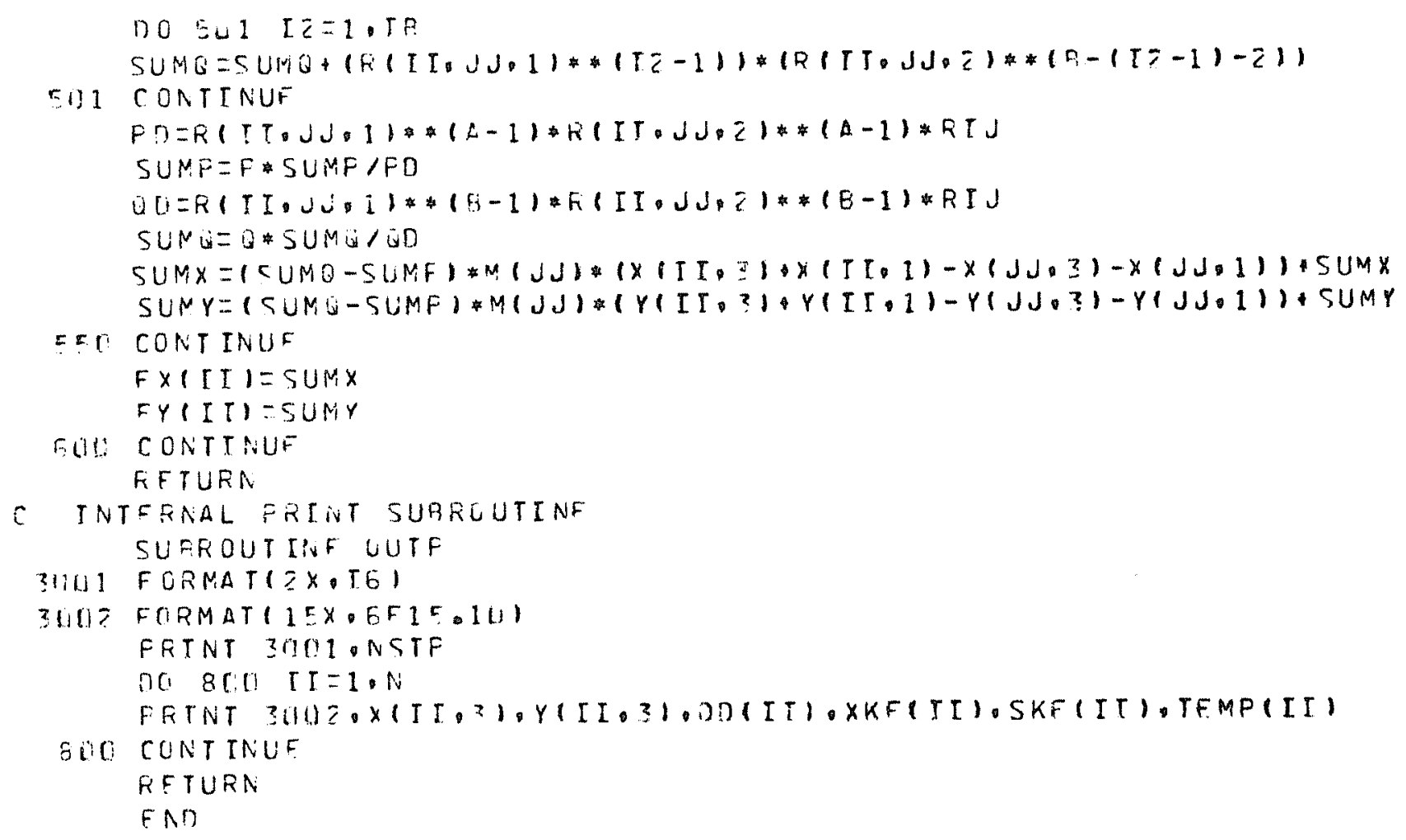




\begin{tabular}{|c|c|c|}
\hline $\begin{array}{l}\text { BIBLIOGRAPHIC DATA } \\
\text { SHEET }\end{array}$ & $\begin{array}{l}\begin{array}{l}\text { 1. Report No. } \\
\text { W IS-CS }-72-164\end{array} \\
\end{array}$ & 3. Recipient's Accession No. \\
\hline \multirow{2}{*}{\multicolumn{2}{|c|}{$\begin{array}{l}\text { 4. Title and Subticle } \\
\text { Discrete Bars, Conductive Heat Transfer, and Elasticity }\end{array}$}} & $\begin{array}{l}\text { 5. Report Date } \\
\text { November } 1972\end{array}$ \\
\hline & & 6. \\
\hline \multicolumn{2}{|c|}{$\begin{array}{l}\text { 7. Author(s) } \\
\text { Donald Greenspan }\end{array}$} & $\begin{array}{l}\text { 8. Performing Organization Rept. } \\
\text { No. }\end{array}$ \\
\hline \multirow{2}{*}{\multicolumn{2}{|c|}{$\begin{array}{l}\text { 9. Performing Organization Name and Address } \\
\text { Computer Sciences Department } \\
\text { The University of W isconsin } \\
1210 \text { West Dayton Street } \\
\text { Madison, Wisconsin } 53706\end{array}$}} & 10. Project/Task/Work Unit No. \\
\hline & & 11. Contract/Grant No. \\
\hline \multirow{2}{*}{\multicolumn{2}{|c|}{ 12. Sponsoring Organization Name and Address }} & $\begin{array}{l}\text { 13. Type of Report \& Period } \\
\text { Covered }\end{array}$ \\
\hline & & 14. \\
\hline
\end{tabular}

15. Supplementary Notes

16. Abstracts

Heat transfer and elasticity are modelled from a discrete point

of view. Computer examples using bars are given to show the feasibility

of the models. The dynamical equations are discrete and energy conserving.

17. Key Words and Document Analysis. 17a. Descriptors

Elasticity, heat transfer, numerical analysis.

17b. Identifiers/Open-Ended Terms

17c. COSATI Field/Group

\begin{tabular}{|c|c|c|}
\hline 18. Availability Statement & $\begin{array}{l}\text { 19. Security Class (This } \\
\text { Report) } \\
\text { UNCLASSIFIED }\end{array}$ & $\begin{array}{l}\text { 21. No. of Pages } \\
30\end{array}$ \\
\hline Avallable to the public. & $\begin{array}{l}\text { 20. Security Class (This } \\
\text { Page } \\
\text { UNCLASSIFIED }\end{array}$ & 22. Price \\
\hline
\end{tabular}


